\title{
Characterizing the Impact of Underwater Glider Observations on the Navy Coastal Ocean Model (NCOM) in the Gulf Stream Region
}

\author{
by \\ Lieutenant Kyle Robert Kausch, United States Navy \\ B.S., Boston College, 2013
}

Submitted to the Department of Earth, Atmospheric and Planetary Sciences in partial fulfillment of the requirements for the degree of

Master of Science

at the

MASSACHUSETTS INSTITUTE OF TECHNOLOGY

and the

WOODS HOLE OCEANOGRAPHIC INSTITUTION

September 2021

(C)2021 Kyle Robert Kausch. All rights reserved.

The author hereby grants to MIT and WHOI permission to reproduce and to distribute publicly paper and electronic copies of this thesis document in whole or in part in any medium now known or hereafter created.

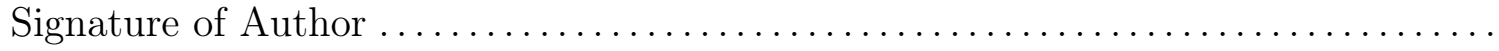

Joint Program in Oceanography/Applied Ocean Science and Engineering

Massachusetts Institute of Technology \& Woods Hole Oceanographic Institution

August 13, 2021

Certified by

Dr. Robert E. Todd

Thesis Supervisor

Associate Scientist, Woods Hole Oceanographic Institution

Accepted by

Prof. Glenn R. Flierl

Chair, Joint Committee for Physical Oceanography Massachusetts Institute of Technology \& Woods Hole Oceanographic Institution 


\title{
Characterizing the Impact of Underwater Glider Observations on the Navy Coastal Ocean Model (NCOM) in the Gulf Stream Region
}

by

\author{
Lieutenant Kyle Robert Kausch, United States Navy
}

Submitted to the Department of Earth, Atmospheric and Planetary Sciences
on August 13, 2021, in partial fulfillment of the
requirements for the degree of
Master of Science

\begin{abstract}
As the western boundary current of the North Atlantic, the Gulf Stream is a wellestablished area of interest for the United States Navy, predominately due to its proximity to the continental shelf and the associated challenges of acoustic propagation across large property gradients. Autonomous underwater gliders conduct routine, high-resolution surveys along the U.S. East Coast, including within the Gulf Stream. These observations are assimilated into the operational Navy Coastal Ocean Model (NCOM). An investigation of the forecast-to-nowcast changes in the model for 2017 demonstrates the impact of the observations on the model. The magnitude of model change as a function of distance from nearest new observation reveals relatively large impact of glider observations within a radius of $\mathcal{O}(100) \mathrm{km}$. Glider observations are associated with larger local impact than Argo data, likely due to glider sampling focusing on large spatial gradients. Due to the advective nature of the Gulf Stream system, the impact of glider observations in the model is anisotropic with larger impacts extending downstream from observation locations. Forecast-to-nowcast changes in modeled temperature, salinity, and density result in improved agreement between observed and modeled ocean structure within the upper $200 \mathrm{~m}$ over the 24 hours between successive model runs.
\end{abstract}

Thesis Supervisor: Dr. Robert E. Todd

Title: Associate Scientist, Woods Hole Oceanographic Institution 


\section{Acknowledgments}

This research was funded via the United States Navy's Civilian Institution Program with the Massachusetts Institute of Technology/Woods Hole Oceanographic Institution Joint Program (MIT/WHOI JP).

Glider observations and analyses have been generously supported by the National Science Foundation (OCE-0220769, OCE-1558521, OCE-1633911, OCE-1923362), NOAA's Global Ocean Monitoring and Observing Program (NA14OAR4320158, NA19OAR4320074), the Office of Naval Research (N000141713040), Eastman Chemical Corporation, WHOI's Oceans and Climate Change Institute, and the W. Van Alan Clark, Jr. Chair for Excellence in Oceanography at WHOI (awarded to Breck Owens).

Credit for the success of the Spray glider missions is owed to several individuals, including Patrick Deane, Joleen Heiderich, Raymond Graham, Larry George, Ben Hodges, and Breck Owens at WHOI and Jeff Sherman, Dan Rudnick, Ben Reineman, Guilherme Castelão, and Evan Randall-Goodwin of the Instrument Development Group at the Scripps Institution of Oceanography. The Physical Oceanography Division at NOAA's Atlantic Oceanographic and Meteorological Laboratory (AOML), the University of Miami's Rosenstiel School of Marine and Atmospheric Science (RSMAS), the East Carolina University Coastal Studies Institute, and North Carolina State University's Center for Marine Sciences and Technology (CMAST) provided laboratory space for glider operations.

Thank you Lea Locke-Wynn, Fleet Numerical Meteorology and Oceanography Center (FNMOC), for providing a complete dataset of RNCOM output for a yearlong analysis.

Thank you Frank Baker, Deputy Executive, Director Oceanographer and Navigator of the Navy (N2N6EDB), and Jay Wallmark, Director, Oceanographic Department, Naval Oceanographic Office (NAVOCEANO), for coordination and delivery of the NAVOCEANO Slocum glider data used in this analysis.

I especially want to thank my advisor, Robert Todd, for his guidance and dedica- 
tion to my learning experience over the last two years. I arrived to the program six years after completing undergrad and very rusty in the realm of academics. Robert always made time to provide assistance, whether for research or classwork, for even the most trivial of questions. He has been instrumental in my development as a student, researcher, and oceanographer. He was considerate of my second full-time job as a father and husband, particularly as we tackled the issues of the COVID-19 pandemic. However, it should be noted that one of the selling points of Robert's work when I first arrived was that I would get field work opportunities in warm weather. As it turned out, I only had two experiences deploying or recovering gliders. The first was a January recovery near the New England shelf (not warm), and the second was a trip to Miami when it was so cold iguanas were falling out of trees!

I owe significant gratitude to my classmates and friends within the Joint Program. Without my cohort in Physical Oceanography - Cora Hersh, Jinshi Chen, Michael Dotzel, Alan Gaul, Glenn Liu, Lukas Lobert, Pad Poemnamthip, Mason Rogers - I would not have made it through classes, and that is not an exaggeration. While I will miss our chats on the sixteenth floor of the Green Building most, our pandemic Zoom meetings to discuss problem sets brought sanity to my isolation and allowed me to laugh and socialize at a time when it was desperately needed. I would also like to thank my fellow Navy students, especially Pete Roemer, Jacob Heuss, Jeff Grabon, Bradli Howard, Tim Getscher, who made balancing our roles as Navy officers and students easier and enjoyable.

This entire experience would not have been possible were it not for the love and support of my family. Since I first decided to apply to the Joint Program almost four years ago, my wife Tricia has expertly handled the stresses and challenges of keeping our life in balance. She has put up with long nights of studying and writing papers and a move from Hawaii to Boston, all while raising our two daughters. Thank you for constantly listening to my complaints and offering advice along the way, I know it must have been tough feigning interest at times. To Adelaide and Maeve, thank you for providing love and joy through the times of the pandemic, it certainly made working from home a lot easier. 


\section{Contents}

1 Introduction $\quad 15$

2 Model and Observations 21

2.1 Regional Model: NCOM . . . . . . . . . . . . . . . 21

2.2 Glider Observations . . . . . . . . . . . . . . . . . . . 23

2.2.1 Spray gliders (WHOI) . . . . . . . . . . . 23

2.2.2 Slocum gliders (NAVOCEANO) . . . . . . . . . . 26

2.3 Argo Observations ...................... 27

3 Analysis and Results $\quad 29$

3.1 Forecast-to-Nowcast Changes in Simulated Fields . . . . . . . . . . . 29

3.2 Spatial Impacts of Observations . . . . . . . . . . . . . . . . . 33

3.2.1 One-dimensional horizontal length scale . . . . . . . . . . . 33

3.2.2 Impact of Argo Observations . . . . . . . . . . . . . . 38

3.2.3 Impact in Two-Dimensional Coordinate System . . . . . . . . 38

3.3 NCOM Improvement from Observations . . . . . . . . . . . . 46

3.3.1 Statistical Significance of Nowcast Improvement . . . . . . . . 47

4 Summary and Future Work $\quad 53$ 
THIS PAGE INTENTIONALLY LEFT BLANK 


\section{List of Figures}

1-1 Bathymetry of the Gulf Stream region along the US East Coast with the NCOM US East domain indicated by the black box. (a) Trajectories of all WHOI-operated Spray gliders (blue) and NAVOCEANOoperated Slocum gliders (green), as well as the location of all Argo profiles (cyan) during 2017. Highlighted in yellow is a segment of glider observations from 24-26 April 2017, for which observations are shown in Figure 2-2. The mean 40-cm absolute dynamic height (ADT) contour (red) delineates the mean position of the Gulf Stream. (b) Streamwise coordinate system, as discussed in Section 3.2.3. Thin red lines are drawn every $20 \mathrm{~km}$ in the cross-stream direction and every $100 \mathrm{~km}$ in the along-stream direction as measured relative to the $40-\mathrm{cm} \mathrm{SSH}$ contour (bold red as in $(\mathrm{a}))$. . . . . . . . . . . . . . . . 19

2-1 Horizontal transects of (a) temperature, (b) salinity and (c) potential density along $72.1010^{\circ} \mathrm{W}$ in the NCOM US East nowcast for 27 April 2017. The area outlined in red indicates the horizontal and vertical extent of the glider observations shown in Fig. 2-2. . . . . . . . . .

2-2 (a-c) Spray glider observations of $(\mathrm{a}, \mathrm{d})$ temperature, $(\mathrm{b}, \mathrm{e})$ salinity, and (c,f) potential density from 24-26 April 2017 along the yellow transect in Fig. 1-1, and ( $\mathrm{d}-\mathrm{f})$ the approximately coincident model nowcast fields from Fig. 2-1. Black contours are isopycnals with a spacing of $0.5 \mathrm{~kg} \mathrm{~m}^{-3}$ and the $26.0 \mathrm{~kg} \mathrm{~m}^{-3}$ isopycnal in bold. . . . . . . . . . 26 
3-1 (a) 24-hour-ahead forecast and (b) nowcast of temperature at $30 \mathrm{~m}$ for 0000Z on 27 April 2017. Glider trajectories (in black) extend from one week before the model run to the day of. Shown in (c) are temperature differences from forecast to nowcast, as well as an indication of the locations of newly available glider observations for the nowcast (yellow segment of glider trajectory). . . . . . . . . . . . . . .

3-2 (a) 24-hour-ahead forecast and (b) nowcast of salinity at $30 \mathrm{~m}$ for $0000 \mathrm{Z}$ on 27 April 2017. Glider trajectories (in black) extend from one week before the model run to the day of. Shown in (c) are salinity differences from forecast to nowcast, as well as an indication of the locations of newly available glider observations for the nowcast (yellow segment of glider trajectory). . . . . . . . . . . . . . . .

3-3 (a) 24-hour-ahead forecast and (b) nowcast of potential density $\left(\sigma_{\theta}\right)$ at $30 \mathrm{~m}$ for 0000Z on 27 April 2017. Glider trajectories (in black) extend from one week before the model run to the day of. Shown in (c) are $\sigma_{\theta}$ differences from forecast to nowcast, as well as an indication of the locations of newly available glider observations for the nowcast (yellow segment of glider trajectory). . . . . . . . . . . . . . .

3-4 Normalized root-mean-square (RMS) changes from $\tau_{24}$ to $\tau_{00}$ for (a) temperature, (b) salinity, and (c) potential density at the surface. In all panels, the black transect denotes the PEACH glider sampling pattern. The inset in (b) shows details of RMS salinity changes along the PEACH transect. . . . . . . . . . . . . . . . .

3-5 Histogram of RMS-averaged impact and great-circle distance from observation, for temperature, salinity and potential density at $(\mathrm{a}-\mathrm{c}) 30$ $\mathrm{m}$ and $(\mathrm{d}-\mathrm{f}) 200 \mathrm{~m}$ depth. Nonlinear exponential fits are annotated in black with red star indicating the decay length scale for given variable and depth. . . . . . . . . . . . . . . . . . 
3-6 Normalized RMS-averaged impacts as a function of great-circle distance from observation, for temperature, salinity and potential density; $(\mathrm{a}-\mathrm{c})$ are glider impacts, $(\mathrm{d}-\mathrm{f})$ are Argo impacts. Color coding indicates the different depth range regimes: 0-200 m (black), 250-500 m (red), 600-2000 m (blue), 2500-5000 m (green). . . . . . . . . .

3-7 Left panels $(\mathrm{a}-\mathrm{c})$ are the normalized nonlinear fit coefficients as defined by Equation 3.1 for temperature, salinity and potential density, respectively, as a function of depth. Length scale $(L)$ is in black, initial value $(A)$ in bold red, and asymptotic value $(B)$ in red. Right panels $(\mathrm{d}-\mathrm{f})$ show model variability with depth as given by the standard deviation of the time mean for each corresponding variable. Gray shaded region indicates those areas where the exponential fit is most valid to describe observational impact. . . . . . . . . . . . . . . .

3-8 Two-dimensional contour plot of RMS temperature impact at $30 \mathrm{~m}$ depth. Black dashes at $\Delta x=0$ and $\Delta y=0$ indicate location of histograms in Figs. 3-9 and 3-10. . . . . . . . . . . . . . . . . . . 40

3-9 Histograms of $\Delta_{R M S}$ forecast-to-nowcast changes at $30 \mathrm{~m}$ in (a,d) temperature, (b,e) salinity, and $(c, f)$ potential density, binned by $(a-c)$ along-stream and $(\mathrm{d}-\mathrm{f})$ cross-stream distance from the nearest glider observation. Positive (negative) along-stream distances correspond to nearest glider observations downstream (upstream) of a model grid point. Positive (negative) cross-stream distances correspond to nearest glider observations offshore (onshore) of a model grid point. Black and red stars indicate the decay length scales for positive and negative directions. Red and black dashed lines indicate the mean outer values of the histogram for $|\Delta y|>200 \mathrm{~km}$ and $|\Delta x|>100 \mathrm{~km}$, examined further in Fig. 3-12. . . . . . . . . . . . . . . . . . 
3-10 Normalized RMS-averaged forecast-to-nowcast change for each model depth level for the two-dimensional coordinate system. Temperature, salinity and potential density are displayed for all depths in the alongstream $(\mathrm{a}-\mathrm{c})$ and cross-stream $(\mathrm{d}-\mathrm{f})$ directions. Color coding indicates the different depth range regimes: 0-200 m (black), 250-500 m (red), 600-2000 m (blue), 2500-5000 m (green). . . . . . . . . . . . .

3-11 Averaged two-dimensional histograms from 0-200 $\mathrm{m}$ for temperature, salinity, and potential density in the along-stream $(\mathrm{a}-\mathrm{c})$ and crossstream $(\mathrm{d}-\mathrm{f})$ directions. The corresponding fits and stars indicate the exponential fit and subsequent average decay length scales for the entire depth range in the positive (red) and negative (black) directions. . . .

3-12 Asymptotic values as a function of depth for temperature, salinity, and potential density in the along-stream direction $(\mathrm{a}-\mathrm{c})$ and cross-stream direction (d-f). Solid black (red) lines indicate positive (negative) mean values of the histogram, and corresponding shading indicates standard deviation of the same. Dotted black (red) lines indicate those exponential asymptotic values $(B)$ for positive (negative) fits that fall within 2 standard deviations of the mean. . . . . . . . . . . .

3-13 Nowcast versus forecast comparison on 09 September 2017. Interpolated forecast (blue) and nowcast (red) profiles are shown with observations from one glider profile (yellow) at $2032 \mathrm{Z}$ for (a) temperature, (b) salinity, and (c) potential density. Differences between given model run and observation are shown for (d-f) temperature, salinity, and potential density. . . . . . . . . . . . . . . . . .

3-14 Forecast error (blue) and nowcast error (red) for (a,c,e) temperature, salinity, and potential density. Statistical significance between loss functions represented by a Diebold-Mariano test statistic value $\left(S_{1}\right.$; black) greater than the critical value at 95\% significance (1.645) for (b,d,f) temperature, salinity, and potential density. . . . . . . . 51 


\section{List of Tables}

2.1 Glider observational statistics for 2017. . . . . . . . . . . . . . 27 
THIS PAGE INTENTIONALLY LEFT BLANK 


\section{Chapter 1}

\section{Introduction}

Western boundary currents play a key role in the global climate system by redistributing heat from the tropics to the subtropics and subpolar regions (Imawaki et al., 2013; Kwon et al., 2010) and by transferring heat into the atmosphere. As the western boundary current of the North Atlantic subtropical gyre, the Gulf Stream is a major component of the Atlantic Meridional Overturning Circulation (Cunningham et al., 2007), bringing warm and saline waters from the tropics poleward to higher latitudes. The current begins as a topographically constrained jet in the Florida Strait and then flows along the continental margin before it departs from the US East Coast at Cape Hatteras, North Carolina, becoming a free-flowing, meandering current that sheds large eddies. The spatial and temporal variability of the Gulf Stream increases as it evolves downstream (e.g., Andres, 2016), resulting in significant temperature and salinity fluctuations along the continental margin, either directly via interaction of coastal flows with the Gulf Stream (e.g., Todd, 2020) or indirectly via mesoscale eddies (e.g., Gawarkiewicz et al., 2018).

Given the longstanding strategic value of operating within or near the shelfbreak

environment (Alvarez, 1969), the US Navy has invested in understanding western boundary currents and their associated oceanographic properties. Acoustic propagation along the shelf is important to naval operations and planning, yet changes in the sound speed field due to the spatial and temporal variation of the shelf-break front (Lynch et al., 2003; Colin et al., 2013) can make analysis of the shallow-water 
environment particularly complex and difficult to predict. Similarly, other small-scale aspects of military operations (e.g., ship routing, search and rescue) can be improved by the ability to resolve nearshore mesoscale features common to the western boundary current regions (Rhodes et al., 2002).

Understanding western boundary current systems is further limited by the international regulations of scientific research near the shelf. The United Nations Convention for the Law of the Sea (UNCLOS) authorizes countries to restrict marine scientific research within its exclusive economic zone (EEZ), which inhibits access to the continental shelf without additional financial and foreign policy considerations (e.g., country clearances). Projects in other prominent western boundary regions of the world exist (e.g., Rainville et al., 2013; Andres et al., 2017), yet the aforementioned considerations impact extent and duration of projects, especially in the deployment and use of in situ platforms. The Gulf Stream provides unique access to a western boundary current that is predominately within US territorial waters, allowing for lesser restrictions on research opportunities that are better suited for understanding the spatial and temporal variability of the region.

Inconsistent coverage of an area and the persistent need for nearshore forecasting has led to the Navy's heavy reliance on numerical prediction for large areas of the ocean. The Naval Oceanography community has spent over four decades developing ocean prediction capabilities designed for the mesoscale and smaller, to include the nearshore environment, for the purposes of tactical level planning (Burnett et al., 2014). This development yielded capabilities like the Navy Coastal Ocean Model (NCOM), with horizontal and vertical resolution capable of capturing dynamics in the interior and up onto the continental shelf.

While numerical prediction has been critical in improving characterization of the nearshore environment, its value is contingent upon its ability to replicate real-world conditions. Observations of sufficient spatial and temporal frequency provide empirical evidence of ocean conditions for comparison and validation. The ubiquity of satellite remote-sensing has allowed for near-real time, global coverage of sea surface temperature (SST) and sea surface height anomalies (SSHA), and the Navy has used 
ocean frontal analysis (e.g., Olson et al., 1983; Miller, 1994) as one way to characterize this nearshore variability. Yet subsurface conditions, especially areas with large gradients, are still largely unresolved even with techniques to project surface conditions vertically (e.g., the Modular Ocean Data Assimilation System (MODAS); Fox et al., 2002). Sustained in situ observations are needed to constrain subsurface properties and the location of gradients.

For many years, an undersea cable in the Florida Strait (Baringer and Larsen, 2001), ship-based hydrographic surveys (Shoosmith et al., 2005), and transects along the CMV Oleander line between New Jersey and Bermuda (Flagg et al., 2006), have provided key observational constraints on Gulf Stream variability. However, the distances between these locations are large enough to leave much of the Gulf Stream region unconstrained by in situ observations. Observations from Argo profiling floats (Riser et al., 2016; Jayne et al., 2017; Roemmich et al., 2019) amply constrain subsurface conditions in the central basin, but Argo was not designed to adequately resolve narrow western boundary currents (Todd et al., 2019; Goes et al., 2020). In an effort to close the gap in Gulf Stream observations, Spray autonomous gliders have routinely sampled the Gulf Stream since April 2015 (Todd, 2017, 2021; Heiderich and Todd, 2020). To date, thirty-eight glider missions have collected nearly 22,000 profiles while criss-crossing the western boundary current between Miami, FL and Cape Cod, MA.

For areas like western boundary currents with large gradients and significant variability, it is important that model output is representative of the valuable in situ data it is provided. The regularity and extent of the Spray glider program supports research of a dynamic feature in the ocean where the scope of observations is often restricted. Furthermore, the placement of the gliders within the US East Coast NCOM domain enables us to analyze directly the relationship between model and observations. There have been other instances of investigation in a model's capability to accurately predict observed oceanographic features (Kerry et al., 2018; Douglass and Mask, 2019). We aim to determine the spatial extent to which the Spray gliders impact the NCOM model, and further distinguish whether such impacts improve to model accuracy. 
Here we examine the impact of assimilating Spray glider measurements along the US East Coast in the operational NCOM model. Background on NCOM physics and its data assimilation process is detailed in Section 2.1. The collection and datareporting procedures of both Spray and the NAVOCEANO-operated Slocum gliders are detailed in Section 2.2, and a brief overview of the Argo floats is provided in Section 2.3. Section 3.1 investigates the changes between successive NCOM model runs due to observational inputs and provides motivation for determining extent of spatial impacts. Section 3.2 explains how we calculate this impact in both oneand two-dimensions, including demonstration of the anisotropic spatial footprint of observations that results from the highly advective nature of the Gulf Stream system. We compare these impacts with Argo in one-dimension in Section 3.2.2 to demonstrate the differences, and subsequent benefits, of glider sampling in a dynamic environment. Section 3.3 quantifies the improvement on NCOM accuracy following assimilation of additional observations. Section 4 summarizes the results and discusses potential future work. 

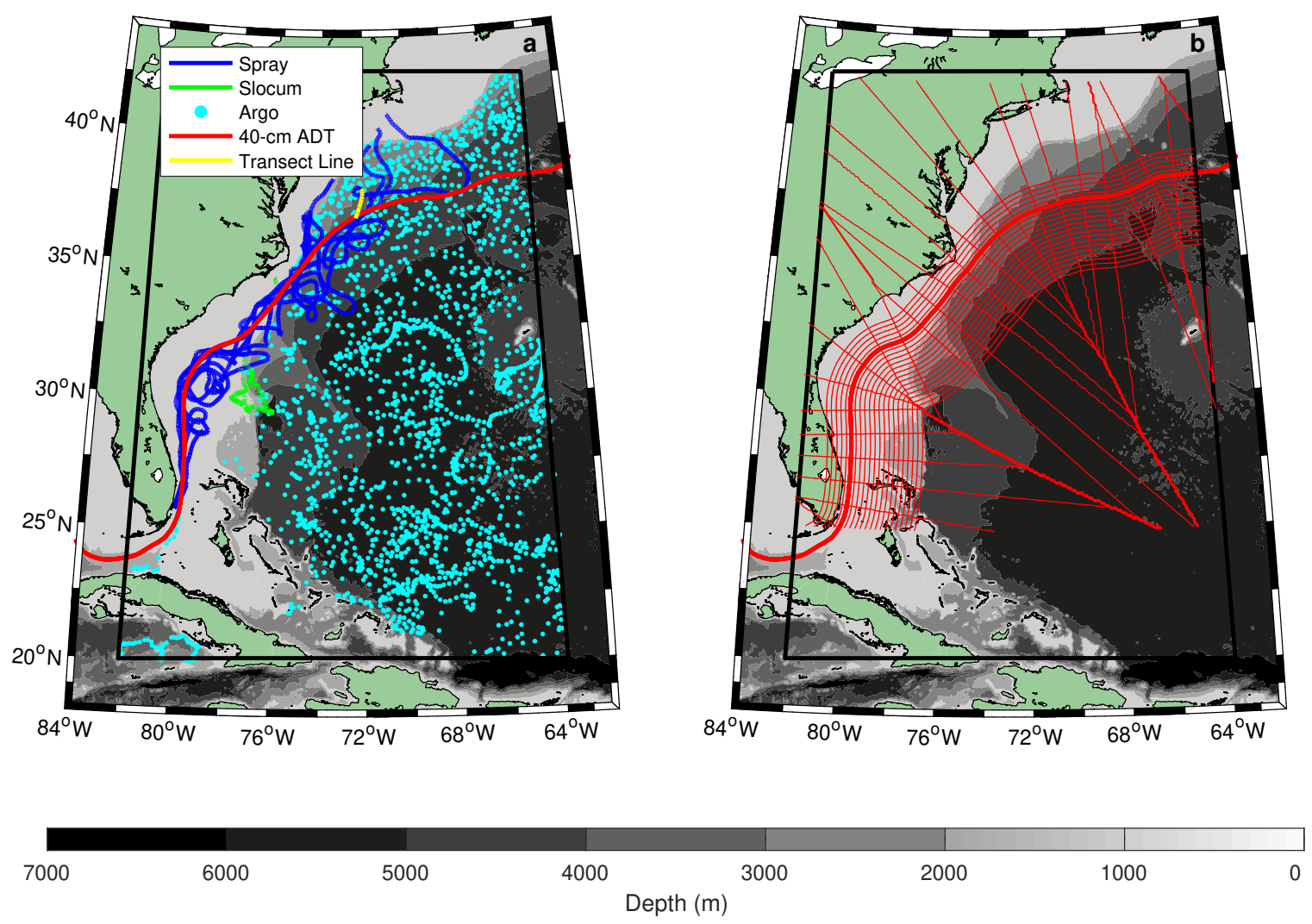

Figure 1-1: Bathymetry of the Gulf Stream region along the US East Coast with the NCOM US East domain indicated by the black box. (a) Trajectories of all WHOIoperated Spray gliders (blue) and NAVOCEANO-operated Slocum gliders (green), as well as the location of all Argo profiles (cyan) during 2017. Highlighted in yellow is a segment of glider observations from 24-26 April 2017, for which observations are shown in Figure 2-2. The mean 40-cm absolute dynamic height (ADT) contour (red) delineates the mean position of the Gulf Stream. (b) Stream-wise coordinate system, as discussed in Section 3.2.3. Thin red lines are drawn every $20 \mathrm{~km}$ in the cross-stream direction and every $100 \mathrm{~km}$ in the along-stream direction as measured relative to the 40-cm SSH contour (bold red as in (a)). 
THIS PAGE INTENTIONALLY LEFT BLANK 


\section{Chapter 2}

\section{Model and Observations}

This chapter describes the numerical model output and observations used in this analysis. Our analysis focuses on 2017, a year in which glider surveys of the Gulf Stream were particularly prevalent; 2017-specific mission statistics are included in Table 2.1.

\subsection{Regional Model: NCOM}

The US Navy Coastal Ocean Model (NCOM) was designed by the Naval Research Laboratory (NRL) and is a free surface, primitive-equation model with hydrostatic, Boussinesq, and incompressible approximations (Barron et al., 2006). NCOM was operated by the US Naval Oceanographic Office (NAVOCEANO) until 2019, after which the Fleet Numerical Meteorology and Oceanography Center (FNMOC) assumed responsibility as the Navy's chief modeling entity. To improve regional and coastal ocean forecasting capabilities, the RELOcatable ocean nowcast/forecast (RELO) system was developed to provide NCOM forecasts at increased spatial resolution within regional domains and to handle the inputs and outputs of data processing and data assimilation (Rowley and Mask, 2014; Smith et al., 2017). The NCOM domain of interest here is referred to as NCOM US East and covers the US East Coast (Fig. 11), spanning from Cuba to Cape Cod $\left(20^{\circ}\right.$ to $\left.42.0978^{\circ} \mathrm{N}\right)$ and eastward to Bermuda $\left(63.9018^{\circ}\right.$ to $\left.82^{\circ} \mathrm{W}\right)$. 
NCOM US East has horizontal resolution of $1 / 30^{\circ}$, or approximately $3 \mathrm{~km}$. The model is run using a hybrid vertical scheme of sigma- and z-coordinates, with a terrain following sigma-coordinate system from the surface to a predetermined sigma$\mathrm{z}$ interface, and fixed z-levels from there to the domain's maximum depth of 5000 m. Model output analyzed here was interpolated to a 40-level z-grid with greater resolution near the surface than at depth. The model forecasts temperature, salinity, and current structure, as well as air-sea interface properties like surface elevation, wind stress, and heat/salt fluxes; other properties can be derived, such as potential density (e.g., Fig. 2-1). Lateral boundary conditions are drawn from the $1 / 12^{\circ}$ global HYbrid Coordinate Ocean Model (HYCOM; Metzger et al., 2014), and surface boundary conditions are obtained from the Coupled Ocean Atmosphere Mesoscale Prediction System (COAMPS; Hodur et al., 2002).

NCOM model runs are released daily at 0000Z, forecasting at 3-hour time intervals for a 96-hour period. These forecasts are updated daily using the Navy Coupled Ocean Data Assimilation (NCODA) three-dimensional variational (3DVAR) system (Cummings and Smedstad, 2013), which assimilates satellite and in situ data made available since the last model run to improve the initial conditions for the next forecast. All observational fields are analyzed concurrently, undergoing automated quality control checks in which each new observation is verified against the first guess of a previous NCOM forecast. Climatological fields are used to determine a probability of error for each observation, and, in cases where observations are limited, they can be used to generate synthetic temperature and salinity profiles based on SST and SSH observations (Fox et al., 2002). The assimilation and analysis of the incoming observations are incrementally applied (Bloom et al., 1996) during a model hindcast run; by the time the updated nowcast is released, all additions of data have been reflected in the model. The global HYCOM model has a similar data assimilation scheme using the Global Ocean Forecast System 3.0 (GOFS 3.0).

Model output is publicly releasable and made available to the general public. Most data used here were retrieved from the National Oceanic and Atmospheric Administration's (NOAA) National Centers for Environmental Information (NCEI). Output 
for the full 4-day forecast is available as netCDF files within hours of an updated model run. In instances where particular dates or time intervals were unavailable via NCEI, NAVOCEANO was able to provide missing data upon request.
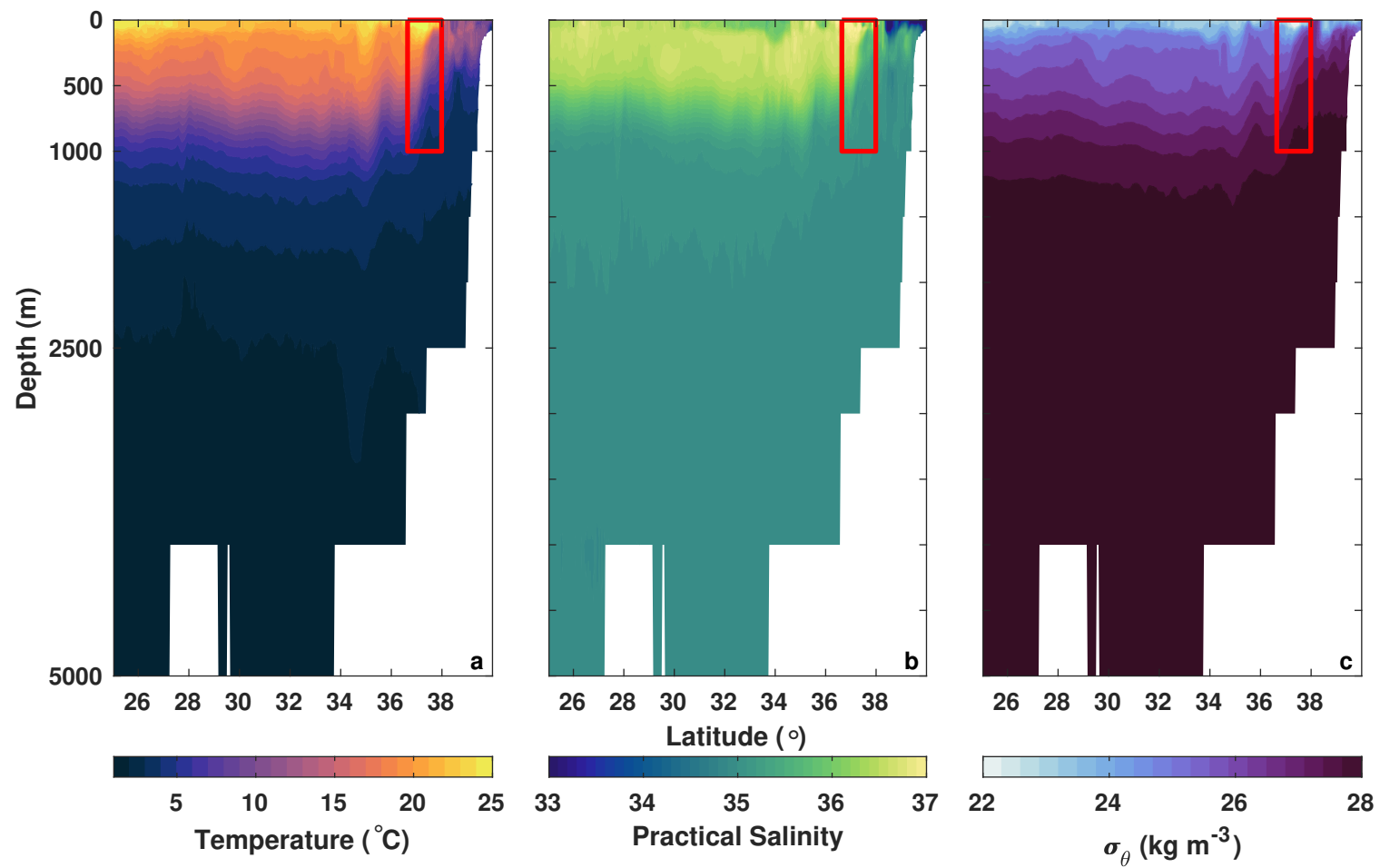

Figure 2-1: Horizontal transects of (a) temperature, (b) salinity and (c) potential density along $72.1010^{\circ} \mathrm{W}$ in the NCOM US East nowcast for 27 April 2017. The area outlined in red indicates the horizontal and vertical extent of the glider observations shown in Fig. 2-2.

\section{$2.2 \quad$ Glider Observations}

\subsubsection{Spray gliders (WHOI)}

Spray autonomous underwater gliders (Sherman et al., 2001; Rudnick, 2016) surveyed the Gulf Stream and adjacent waters along the US East Coast throughout 2017. Three of the eight Spray glider missions completed were in support of the NSF-funded 'Processes driving Exchange At Cape Hatteras (PEACH)' project. PEACH gliders repeatedly sampled along and across the continental margin north of Cape Hatteras, North Carolina beginning in April 2017 (Todd, 2020). The five other missions were 
part of an ongoing effort to routinely survey the Gulf Stream along the US East Coast from Miami, Florida to the shelf edge off southern New England (Todd, 2017, 2021; Heiderich and Todd, 2020). Gliders moved through the water at about $0.25 \mathrm{~m} \mathrm{~s}^{-1}$ horizontally and $0.1 \mathrm{~m} \mathrm{~s}^{-1}$ vertically. When steering across the Gulf Stream, gliders were advected downstream at a speed of roughly $1 \mathrm{~m} \mathrm{~s}^{-1}$, resulting in zigzag transects (Fig. 1-1). Typical mission duration was about four months.

As a buoyancy driven platform, a Spray glider executes a series of sawtooth dives, reaching maximum depths up to $1000 \mathrm{~m}$ in deep water or to within a few meters of the bottom in shallower areas. Each glider is equipped with a pumped Sea-Bird 41CP conductivity-temperature-depth (CTD) instrument, measuring temperature, salinity, and pressure on the ascending portion of the profile at a rate of $1 / 8 \mathrm{~Hz}$. Potential density $\left(\sigma_{\theta}\right)$ is derived from measured temperature and salinity. In 2017, each Spray glider was also equipped with a 1-MHz Nortek AD2CP Doppler current profiler and a Seapoint chlorophyll floroumeter, providing measurements of absolute velocity ( Todd et al., 2017) and chlorophyll a flourescence, respectively. Velocity and chlorophyll measurements are not provided to NAVOCEANO for the NCODA data assimilation process and are not discussed further here. Observations from an example transect across the Gulf Stream near $72^{\circ} \mathrm{W}$ during 24-26 April 2017 (Fig. 2-2a-c) capture the large cross-stream gradients in temperature and salinity that typify the Gulf Stream. This particular transect also captured low salinity water from Mid-Atlantic Bight (MAB) shelf that had been entrained within the Gulf Stream (e.g., Ford et al., 1952; Todd, 2020).

Glider observations are relayed in near-real time each time a glider surfaces using Iridium satellite antennas located within either glider wing. CTD measurements from each profile are decimated by a factor of three to five for near-real time data transmission. We use these decimated data throughout this analysis. Temperature and salinity measurements from each dive are received by the Scripps Institution of Oceanography (SIO) Instrument Development Group (IDG). Every four hours, newly received measurements are sent via email to NAVOCEANO for data assimilation into NCOM via NCODA and the RELO system. Simultaneously, the data are also delivered to 
the Global Telecommunications System (GTS) via the Integrated Ocean Observing System (IOOS) Glider Data Assembly Center (DAC), which provides global access in a publicly accessible database.

Post-processing of real-time glider data is limited to a few automated quality assurance checks once it is transferred to the SIO server. Best estimates of profile locations are calculated from pre- and post-dive GPS fixes, with automated thresholds to flag and interpolate over poor quality or missing fixes. Temperature and salinity checks include global ranges and determining whether the CTD was on or off during the dive. The email delivery method does not include these flags and does not remove flagged data; it is expected that operational users are applying their own quality control checks prior to model assimilation or other use. In the event of a major CTD failure, automated emails from SIO to NAVOCEANO are stopped until the situation is resolved. However, in cases of intermittent periods of erroneous data (i.e., as a result of clogged CTD), regular reporting to NAVOCEANO continues. 

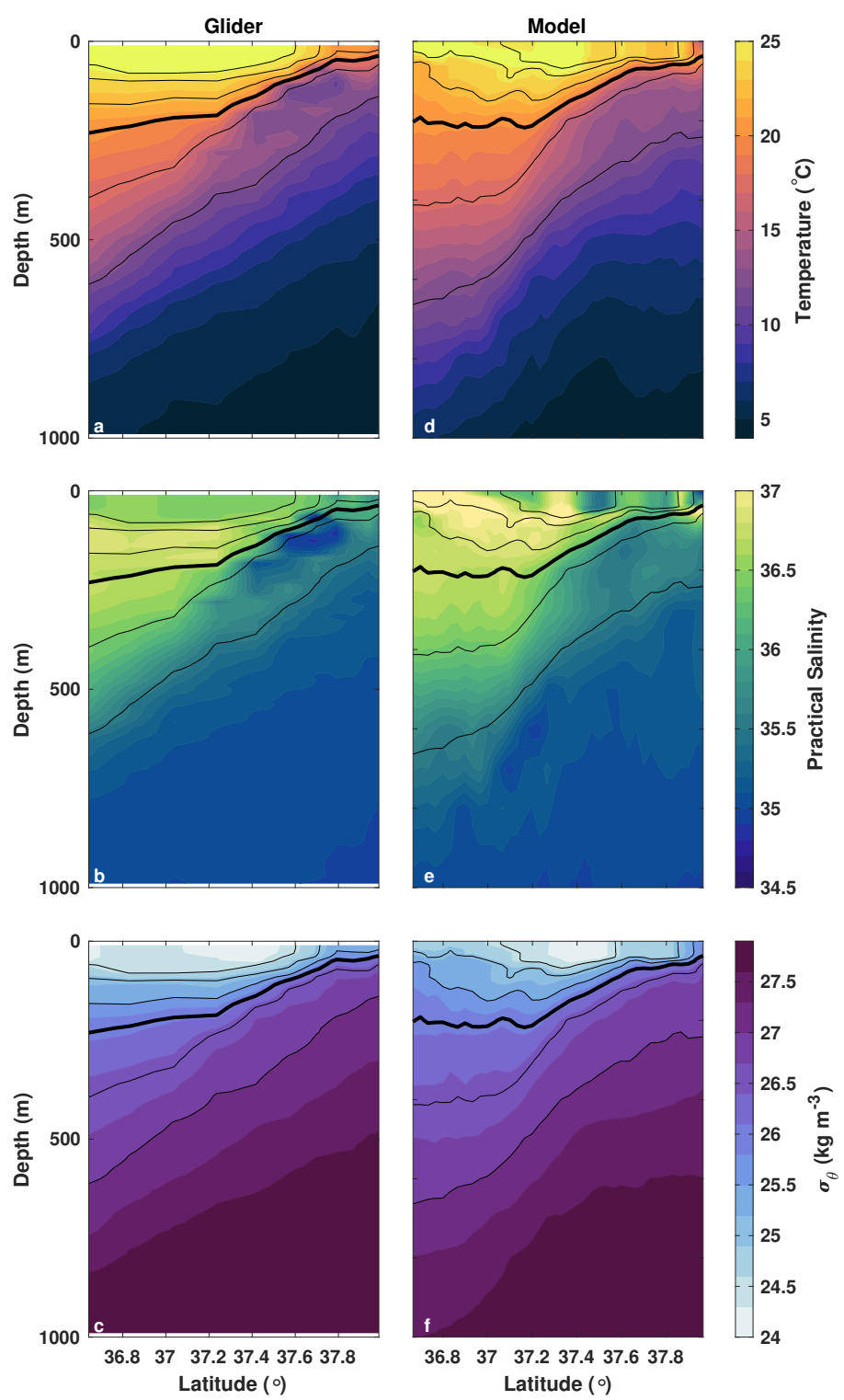

Figure 2-2: $(\mathrm{a}-\mathrm{c})$ Spray glider observations of $(\mathrm{a}, \mathrm{d})$ temperature, $(\mathrm{b}, \mathrm{e})$ salinity, and $(\mathrm{c}, \mathrm{f})$ potential density from 24-26 April 2017 along the yellow transect in Fig. 1-1, and $(\mathrm{d}-\mathrm{f})$ the approximately coincident model nowcast fields from Fig. 2-1. Black contours are isopycnals with a spacing of $0.5 \mathrm{~kg} \mathrm{~m}^{-3}$ and the $26.0 \mathrm{~kg} \mathrm{~m}^{-3}$ isopycnal in bold.

\subsubsection{Slocum gliders (NAVOCEANO)}

Slocum gliders (Webb et al., 2001; Schofield et al., 2007) are another type of buoyancy driven platform that share many parallels in design and function with Spray gliders (Rudnick et al., 2004) and return similar temperature, salinity, and pressure measurements. From 18 October to 13 December 2017, five Slocum gliders operated 
by NAVOCEANO were deployed within the NCOM US East domain. Observations from these gliders are included alongside the Spray glider observations in the following analysis. Unlike the Spray gliders, the Slocum gliders primarily operated in virtual mooring mode at locations seaward of the Gulf Stream (within approximately 100 $\mathrm{km}$ of $30.5^{\circ} \mathrm{N}, 77^{\circ} \mathrm{W}$ ), with a brief, two-day sampling period south of Cape Hatteras from 11 to 13 December 2017 (Fig. 1-1, green trajectories). Full mission statistics for both Spray and Slocum gliders are included in Table 2.1.

\begin{tabular}{|c|c|c|}
\hline & Spray (WHOI) & Slocum (NAVOCEANO) \\
\hline \hline Missions & 8 & 5 \\
\hline Dives & 6,047 & 2,649 \\
\hline Glider Days & 640 & 95 \\
\hline Distance & $21,580 \mathrm{~km}$ & $2,259 \mathrm{~km}$ \\
\hline
\end{tabular}

Table 2.1: Glider observational statistics for 2017.

\subsection{Argo Observations}

In addition to the gliders, Argo profiling floats provide near-real time measurements in the region for NCOM data assimilation. These buoyancy-driven floats typically profile between $2000 \mathrm{~m}$ and the surface once every 10 days, measuring temperature, salinity, and pressure. The Argo observations used in this analysis were obtained from the Argo Global Data Assembly Center (Argo, 2020). During 2017, there were a total of 2,301 Argo observations within the US East domain, ranging from just off the continental shelf to the Atlantic interior (Fig. 1-1, cyan). 
THIS PAGE INTENTIONALLY LEFT BLANK 


\section{Chapter 3}

\section{Analysis and Results}

This chapter evaluates the impact of glider observations on the NCOM US East model. We begin by comparing 24-hour-ahead forecasts to nowcasts at the same valid time, allowing us to identify changes to the simulated ocean properties that presumably result from including newly available observations in each successive model run (Section 3.1). We then estimate the spatial footprint and magnitude of impact of glider observations in the model, and we compare this footprint against that of observations from Argo floats (Section 3.2). Finally, we demonstrate that the nowcast simulations have significantly smaller biases relative to in situ observations than do the 24-hour-ahead forecasts (Section 3.3).

\subsection{Forecast-to-Nowcast Changes in Simulated Fields}

To characterize changes to the NCOM US East simulation in the 24-hour span between subsequent model runs, we first compare 24-hour-ahead forcasts (denoted $\tau_{24}$ ) and nowcasts (denoted $\tau_{00}$ ) at the same valid time and compute differences at each grid point (Figs. 3-1, 3-2, and 3-3). The locations of glider observations tend to coincide with some of the largest changes between model runs, particularly in areas where the gradients are strongest along the Gulf Stream front. For instance, an apparent southward shift in the northern edge of the Gulf Stream between forecast and nowcast resulted in a $6{ }^{\circ} \mathrm{C}$ temperature reduction and a $\sim 2$ PSU salinity increase in the 
vicinity of newly available glider observations on 27 April 2017 (Figs. 3-1, 3-2). Such movement of the Gulf Stream front due to data assimilation was previously noted as a shift in the location at which the $15{ }^{\circ} \mathrm{C}$ isotherm intersects the 200 -m isobath near Cape Hatteras (Todd and Locke-Wynne, 2017).

While the correspondence between observation locations and the model changes on a particular day is encouraging, a more robust analysis is needed to clarify typical impacts of glider observations on the simulations. For temperature, salinity and potential density, we compute the root-mean-square (RMS) changes between forecast and nowcast values at each model grid point, with averaging over calendar year 2017. We normalize these RMS changes by the lateral standard deviation in the time-mean field at each depth. The resulting maps of normalized RMS changes (Fig. 3-4) support the previous single-day comparisons; the largest run-to-run changes occur along the Gulf Stream, where the gradients are large. Furthermore, the presence of the glider observations can be attributed to an increase in model corrections, particularly in the vicinity of Cape Hatteras, where sampling for PEACH was particularly dense. A region of large RMS changes in NCOM aligns well with the PEACH glider transect, which was repeatedly sampled from April through December of 2017 (Fig. 3-4). We note that relatively large run-to-run changes occur well to the east of the PEACH region, but do not extend upstream relative to the Gulf Stream's flow. We examine this directional dependence in observational impact in Section 3.2.3. 

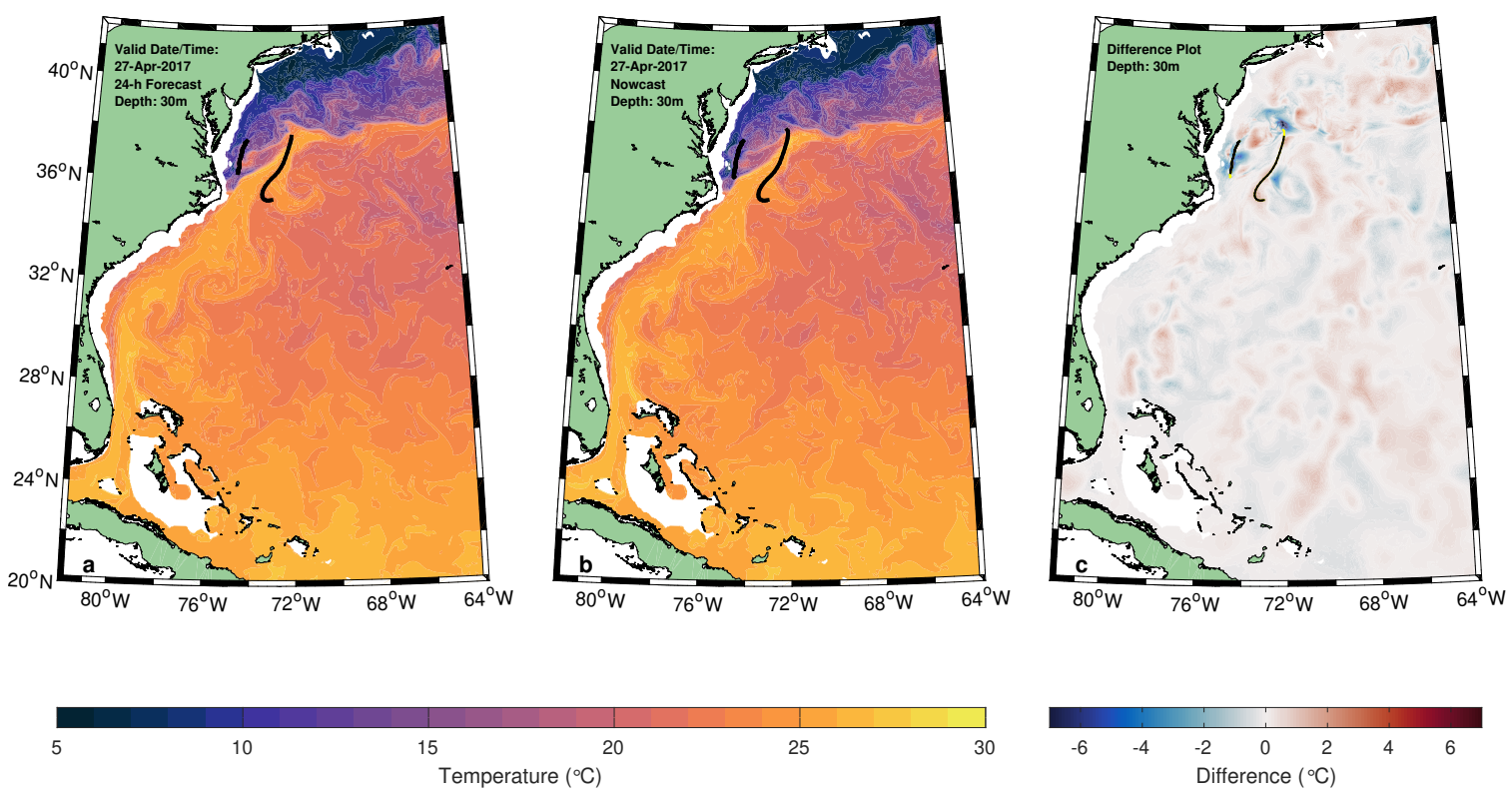

Figure 3-1: (a) 24-hour-ahead forecast and (b) nowcast of temperature at $30 \mathrm{~m}$ for 0000Z on 27 April 2017. Glider trajectories (in black) extend from one week before the model run to the day of. Shown in (c) are temperature differences from forecast to nowcast, as well as an indication of the locations of newly available glider observations for the nowcast (yellow segment of glider trajectory).
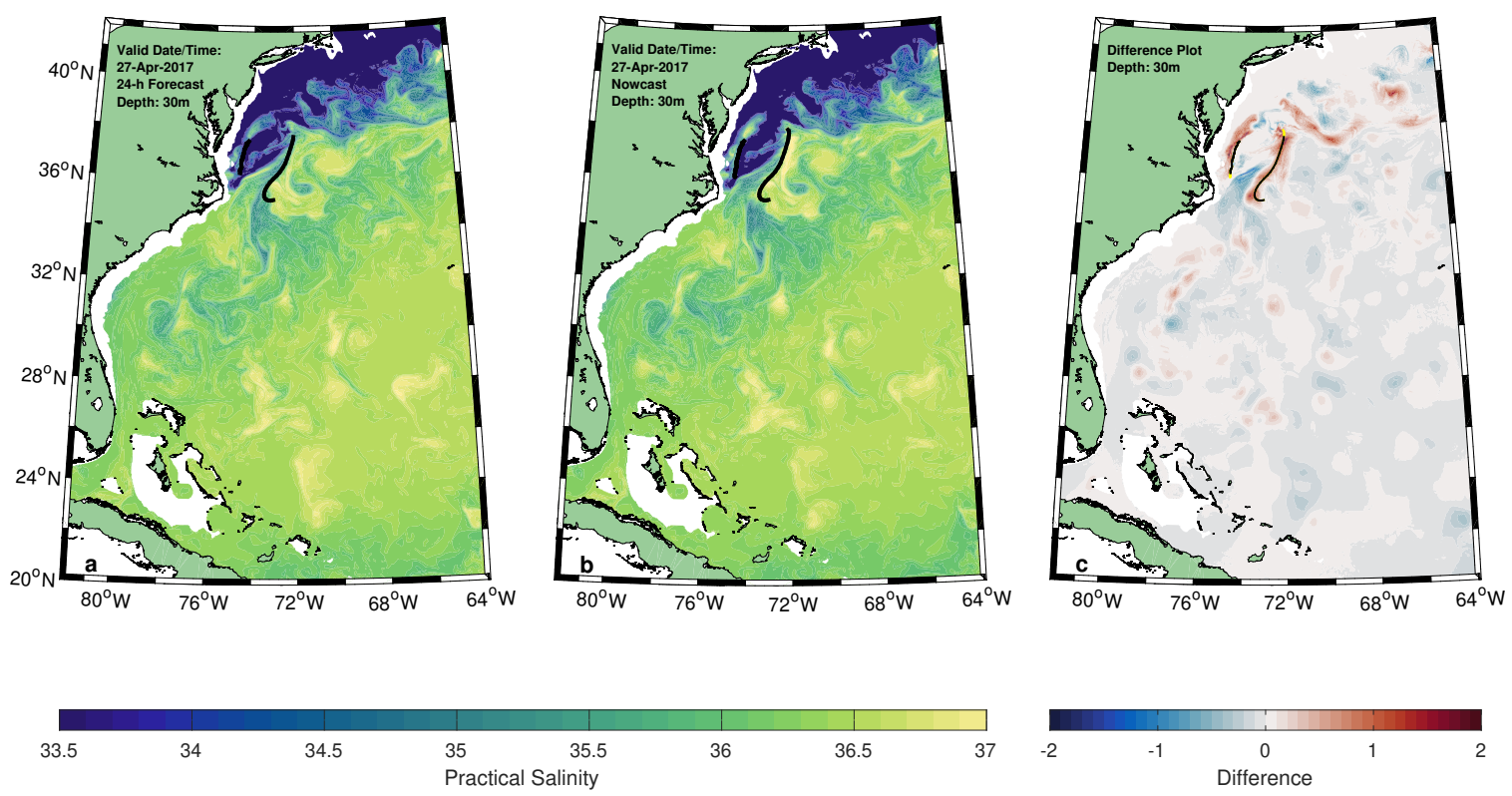

Figure 3-2: (a) 24-hour-ahead forecast and (b) nowcast of salinity at $30 \mathrm{~m}$ for $0000 \mathrm{Z}$ on 27 April 2017. Glider trajectories (in black) extend from one week before the model run to the day of. Shown in (c) are salinity differences from forecast to nowcast, as well as an indication of the locations of newly available glider observations for the nowcast (yellow segment of glider trajectory). 

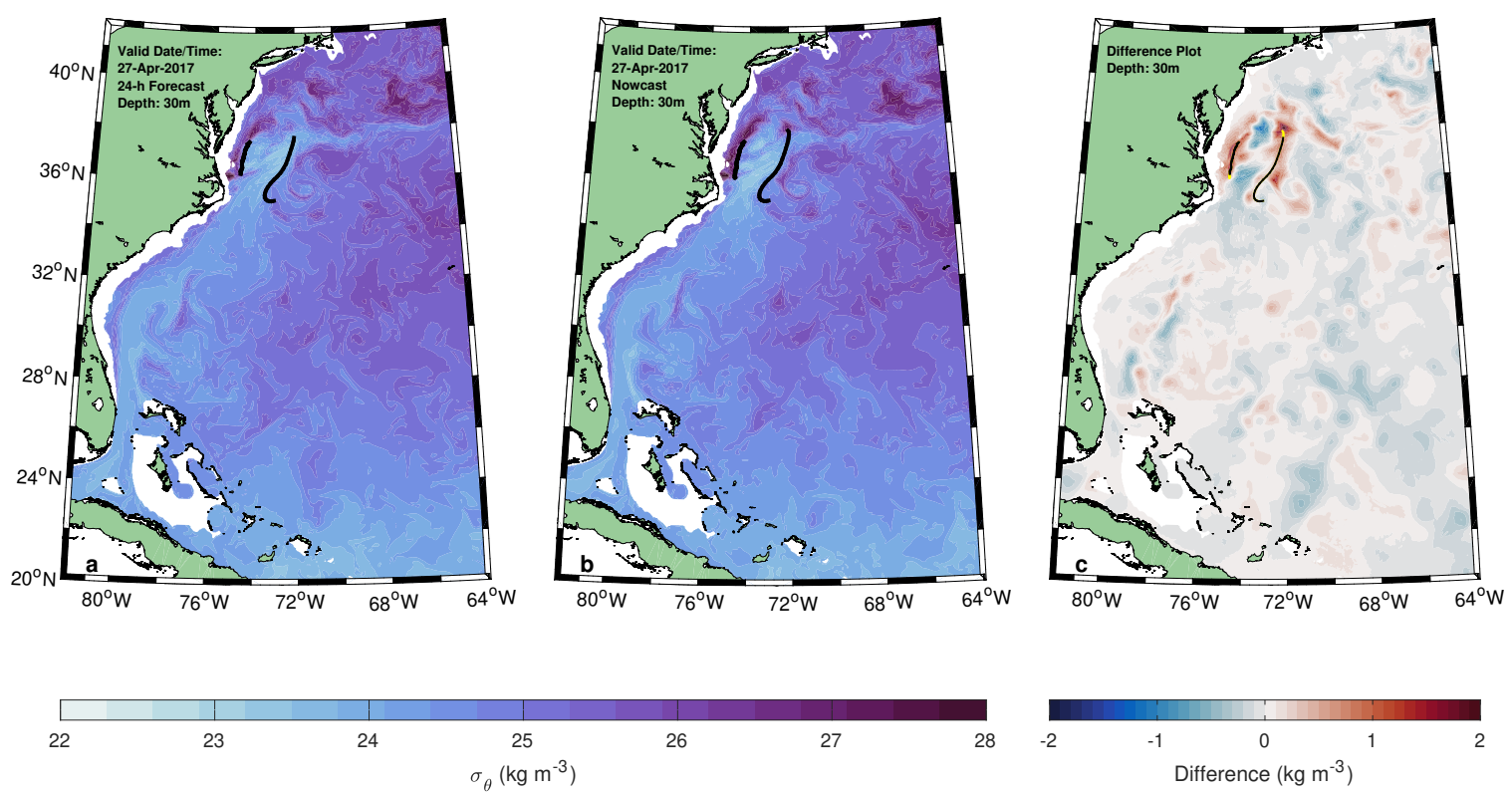

Figure 3-3: (a) 24-hour-ahead forecast and (b) nowcast of potential density $\left(\sigma_{\theta}\right)$ at $30 \mathrm{~m}$ for $0000 \mathrm{Z}$ on 27 April 2017. Glider trajectories (in black) extend from one week before the model run to the day of. Shown in (c) are $\sigma_{\theta}$ differences from forecast to nowcast, as well as an indication of the locations of newly available glider observations for the nowcast (yellow segment of glider trajectory).
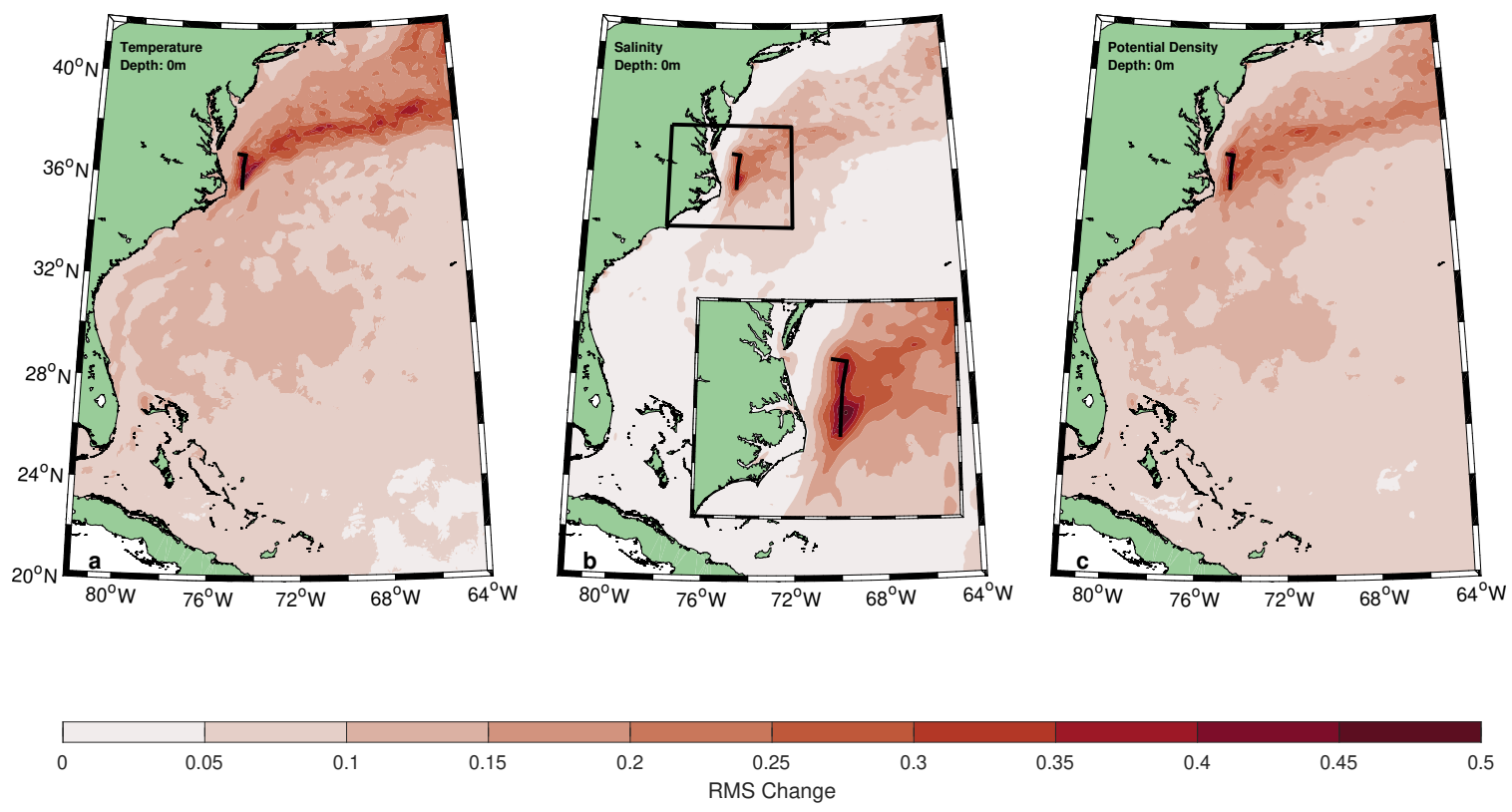

Figure 3-4: Normalized root-mean-square (RMS) changes from $\tau_{24}$ to $\tau_{00}$ for (a) temperature, (b) salinity, and (c) potential density at the surface. In all panels, the black transect denotes the PEACH glider sampling pattern. The inset in (b) shows details of RMS salinity changes along the PEACH transect. 


\subsection{Spatial Impacts of Observations}

We now seek to quantify the spatial extent of glider observations' impact on forecastto-nowcast model changes. Our initial assessment employs an estimation of a onedimensional, horizontal length scale. We use this one-dimensional framework to compare magnitude of impact between gliders and the Argo profiling floats. We then further our analysis by using a two-dimensional coordinate system to focus on the anisotropy of the model physics.

\subsubsection{One-dimensional horizontal length scale}

To evaluate one-dimensional impacts for a given day, we determine the minimum great-circle distance from each model grid point to a glider measurement that was made available for assimilation within the preceding 24 hours. Forecast-to-nowcast changes in the model at each depth are then RMS-averaged by distance to observation with a bin size of $20 \mathrm{~km}$. The resulting histograms (e.g., Fig. 3-5) show how the size of the forecast-to-nowcast change in a particular parameter varies with distance from a glider observation. To more readily compare histograms at different depths, we normalize by the standard deviation of the time-mean field at each depth, with the resulting values denoted here as $\Delta_{R M S}$ (Fig. 3-6a-c).

Based on general shapes of these normalized histograms, we consider four distinct depth ranges. In the first range (0-200 m), histograms exhibit roughly exponential decay; the local impacts, those nearest the newly available observations, are markedly higher than the values at greater distances. This exponential shape suggests a decay of impact with range, motivating further analysis to determine an appropriate scale (see below). The next depth range (250-500 m) maintains the highest impacts locally, but rather than an exponential decay with distance, we now see a more linear trend. The average, normalized magnitude of impact in the 250-500 m and 600-2000 m depth ranges is comparable, likely because glider and other observations (e.g., Argo) from 600-1000 $\mathrm{m}$ are still prominent and thus contribute to local and non-local variation. However, it is important to note that the absolute magnitude at the 600-2000 m 
range is less than at the shallower depths due to the decrease in lateral variance with depth (Fig. 3-7d-f). Additionally, the 600-2000 m depth range does not exhibit decay in response with increasing distance from glider observations, with the largest impacts at intermediate or remote distances. We suspect that this behavior is a result of the generally weak gradients and temporal variability at these depths being reasonably well captured by other components of the operational forecast system (e.g., assimilation of Argo, initialization from global HYCOM, etc.). At depths of 2500-5000 m, which are well outside of the expected glider observational footprint, the normalized forecast-to-nowcast change values are both very small and unchanging with distance from glider observations. We note that while Slocum missions were included in the averaging process and resulting histograms, the inclusion had negligible impact on the results given their relatively low sample size and the general location outside of the Gulf Stream.

The shape of the normalized histograms at depths shallower than $200 \mathrm{~m}$ suggests that a horizontal length scale for glider impact can be estimated using exponential fitting. At each depth we use a nonlinear, least-squares fit of an exponential plus a constant such that

$$
\Delta_{R M S}=A e^{-x / L}+B
$$

where $A$ is distance from a glider observation, $A$ measures the size of the model change in the immediate vicinity of glider observations; $L$ is the lateral scale over which that local impact decays; and $B$ is representative of the non-local ('asymptotic') changes to the model, which are likely attributable to assimilation of other observations (e.g., SSH, SST, Argo). With the majority of the model grid points located within 1000 $\mathrm{km}$ of the nearest observation, the fit focuses on the first $800 \mathrm{~km}$ to better capture the decay scale and avoid those bins with poor averaging. Fits to example histograms (without normalization) for temperature, salinity, and potential density illustrate the decay length scales at $30 \mathrm{~m}$ and $200 \mathrm{~m}$ (Fig. 3-5, black curves and red stars).

We compare the normalized, nonlinear-fit coefficients $(A, B, L)$ at each depth to 
the vertical structure of the model's variability, which we represent by the lateral standard deviation of the time mean fields (Fig. 3-7). For all three variables, the normalized local and remote model changes $(A, B)$ peak in the upper $100 \mathrm{~m}$, where lateral variance is largest (Fig. 3-7d-f). The corresponding decay scales $(L)$ are $\mathcal{O}(100) \mathrm{km}$ in the upper $100 \mathrm{~m}$. From 100 to $200 \mathrm{~m}$, the normalized model changes decrease, indicating that the magnitude of model changes decay more rapidly with depth than does the domain-wide variance. Length scales $(L)$ obtained from the least-squares fit grow in this depth range, likely correspondingly to the transition to the more linear decay with distance from the observations noted above. The high local values and sensible decay scales provided by the exponential fit capture the model's horizontal radius of impact for a given observation, as quantified by the average length scale. Most changes in ocean density occur within this depth range, which typically includes the mixed layer and thermocline, therefore any estimations on length scales are best determined here.

The shapes of the histograms in deeper depth ranges suggest minimal dependence on observational input in the 24 hours preceding the analysis time. Below $200 \mathrm{~m}$, the exponential fit is no longer a valid model for the variables, as evidenced by length scales becoming unrealistically large. Below $500 \mathrm{~m}$, the model exhibits little local impact as the histograms do not exhibit decay with distance. In the 600-2000 m depth range, this may be attributed to Argo observations, climatology, and boundary conditions, which seem sufficient to constrain deep water properties of the model. 

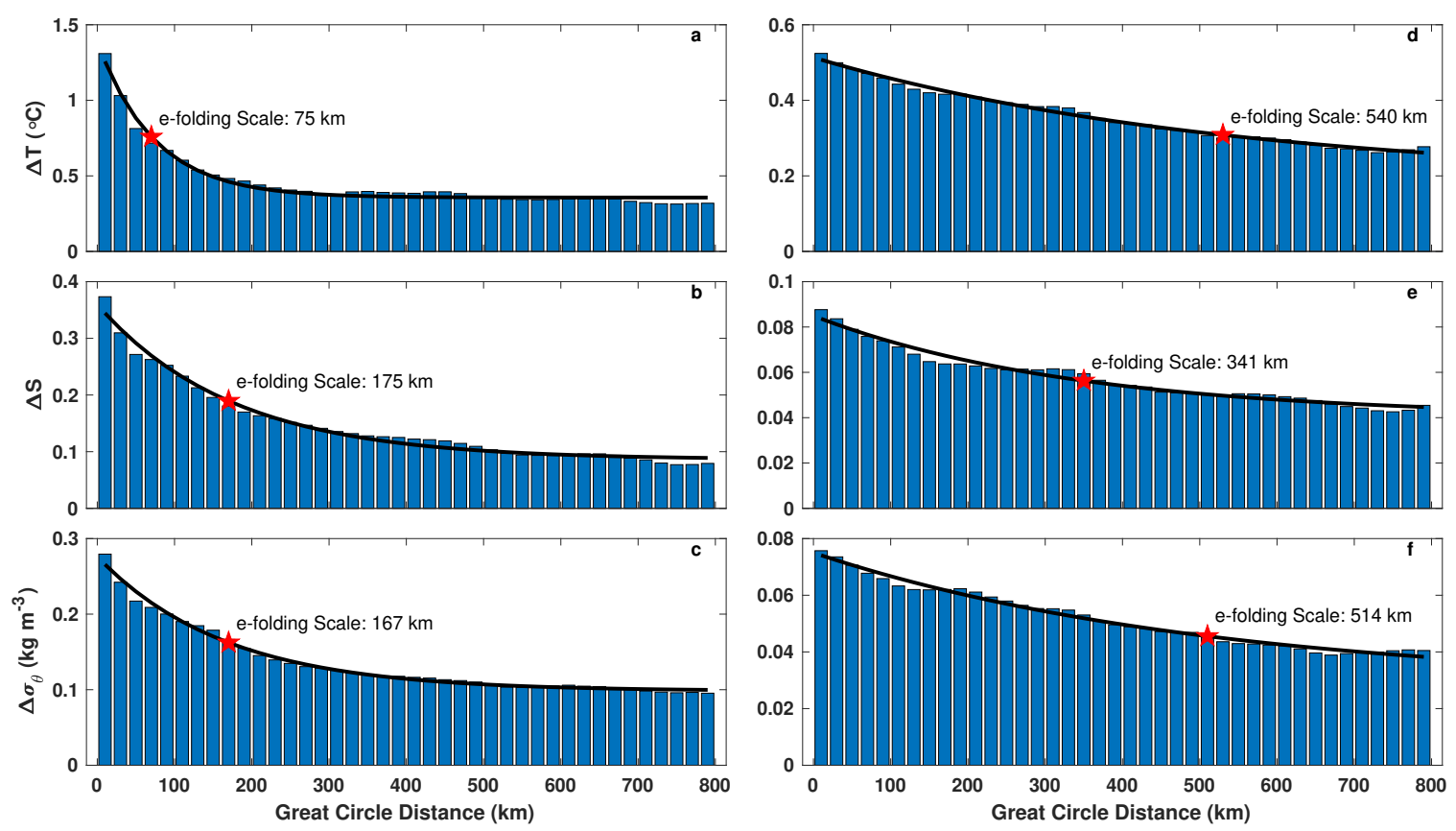

Figure 3-5: Histogram of RMS-averaged impact and great-circle distance from observation, for temperature, salinity and potential density at (a-c) $30 \mathrm{~m}$ and $(\mathrm{d}-\mathrm{f}) 200 \mathrm{~m}$ depth. Nonlinear exponential fits are annotated in black with red star indicating the decay length scale for given variable and depth.
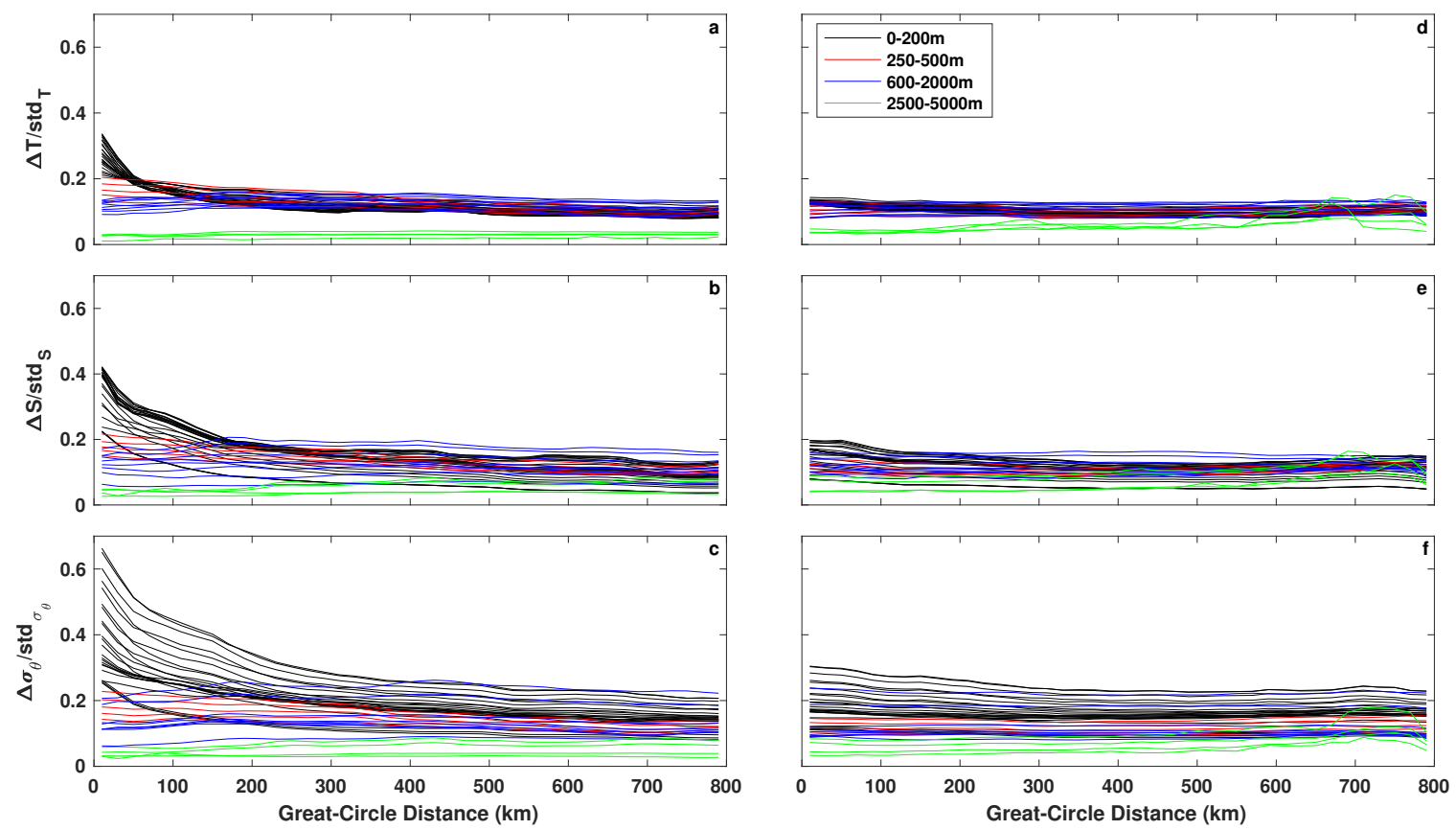

Figure 3-6: Normalized RMS-averaged impacts as a function of great-circle distance from observation, for temperature, salinity and potential density; $(\mathrm{a}-\mathrm{c})$ are glider impacts, $(\mathrm{d}-\mathrm{f})$ are Argo impacts. Color coding indicates the different depth range regimes: 0-200 m (black), 250-500 m (red), 600-2000 m (blue), 2500-5000 m (green). 

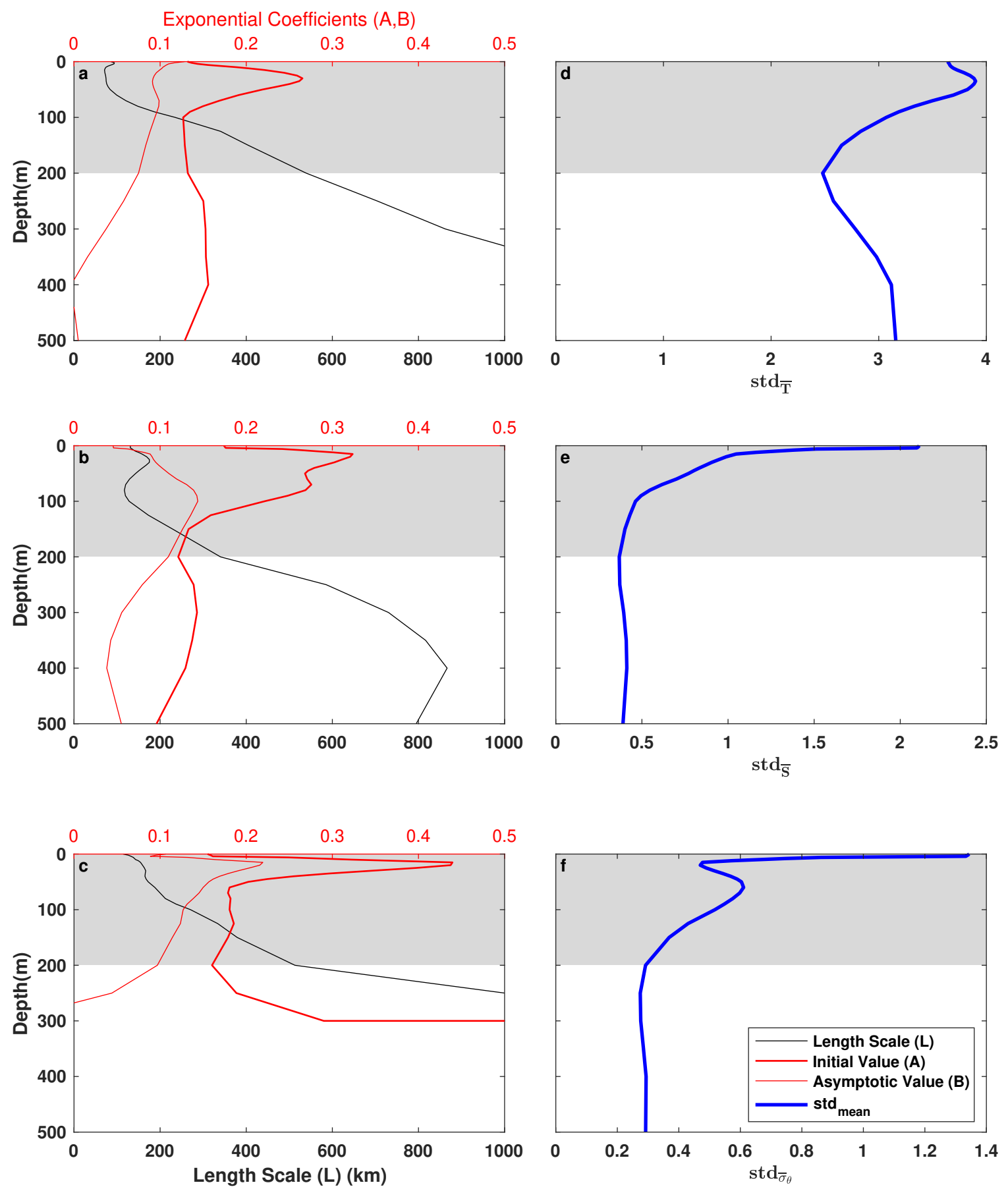

Figure 3-7: Left panels $(\mathrm{a}-\mathrm{c})$ are the normalized nonlinear fit coefficients as defined by Equation 3.1 for temperature, salinity and potential density, respectively, as a function of depth. Length scale $(L)$ is in black, initial value $(A)$ in bold red, and asymptotic value $(B)$ in red. Right panels $(\mathrm{d}-\mathrm{f})$ show model variability with depth as given by the standard deviation of the time mean for each corresponding variable. Gray shaded region indicates those areas where the exponential fit is most valid to describe observational impact. 


\subsubsection{Impact of Argo Observations}

Gliders are not the only platforms routinely providing subsurface data that can constrain operational models. We now consider how forecast-to-nowcast changes in NCOM US East are related to observations from Argo floats. We use the same techniques as in Section 3.2.1 to generate normalized histograms of Argo impact as a function of distance and depth. We then compare the local and remote impacts of Argo observations to those of glider observations (Fig. 3-6d-f).

Argo observations have a notably smaller local impact than do glider observations (Fig. 3-5). At grid points nearest Argo observations, $\Delta_{R M S}$ is approximately a factor of two smaller than for similar distances from glider observations. This discrepancy is likely attributable to the fact that most Argo observations are seaward of the Gulf Stream (Fig. 1-1), where gradients are weaker than those typically sampled by gliders in the Gulf Stream itself. Kerry et al. (2018) similarly emphasize that observations in areas with large variability have high impact and that gliders are among the platforms best suited to provide such observations.

Other aspects of the Argo impact are generally similar to the glider observational impact. The largest Argo impacts were at the depths with the most variability (0$200 \mathrm{~m}$ ). The general shape of the upper level histograms suggest an exponential relationship. Given the spatial distribution of the floats, the magnitude of Argo impact beyond $400 \mathrm{~km}$ becomes affected by other observations which influences the calculated length scales. The remote impacts $(B)$ were of the same magnitude as for the gliders, suggesting as before that these values are representative of other observational inputs the broad scale impact of other assimilated observations.

\subsubsection{Impact in Two-Dimensional Coordinate System}

We now expand upon the one-dimensional analysis of section 3.2 .1 by evaluating impact of glider observations in a two-dimensional coordinate system that accounts for the advective nature of the Gulf Stream, which occupies a large portion of the model domain. Following Heiderich and Todd (2020) and Todd (2021), we use the 
mean position of the 40-cm absolute dynamic height (ADT) contour to define an along-stream coordinate system with origin at $25^{\circ} \mathrm{N}$. For any model grid point or observation location, the cross-stream position $(x)$ is taken to be the minimum great circle distance to the 40-cm ADT contour (positive offshore) and the along-stream position $(y)$ is the distance from the origin to the nearest point along the 40-cm ADT contour (positive downstream). Note that along-stream coordinates become poorly defined at cross-stream distances exceeding the radius of curvature of the $40-\mathrm{cm}$ ADT contour (Fig. 1-1b).

We then compute RMS forecast-to-nowcast changes as a function of along- and cross-stream distance to the nearest glider observation made available within the 24 hours between model runs. To focus on the areas with the largest impact, the domain of the histograms was constrained to $\pm 200 \mathrm{~km}$ in the cross-stream direction and $\pm 500 \mathrm{~km}$ in the along-stream direction, with bin sizes of 25 and $50 \mathrm{~km}$, respectively. Negative values of $\Delta x$ indicate that the nearest observation available from the gliders is onshore of the model point, while positive values of $\Delta x$ indicate observations located offshore. In the along-stream direction, observations that are upstream of the model point correspond to negative values of $\Delta y$ and positive values of $\Delta y$ correspond to observations that are downstream of a model grid point.

An example histogram for temperature at $30 \mathrm{~m}$ depth shows the two-dimensional extent of the observational impact (Fig. 3-8). As seen in the one-dimensional case, the greatest model change is concentrated nearest the observations. Local impact is roughly symmetric across both axes with a decay scale of approximately $100 \mathrm{~km}$ as found in Section 3.2.1. At greater distances, the impacts become more asymmetric; the along-stream direction shows larger model changes downstream of new observations $(\Delta y<0)$. While there are some indications that the along- and crossstream dependence of model sensitivity to observations are linked (e.g., tilted pattern in Fig. 3-8), we will focus on the these two directions independently by considering patterns of histograms with $\Delta x=0$ or $\Delta y=0$. As in Section 3.2.1, we fit the nonlinear function from Eq. 3.1 for $\pm \Delta x$ and $\pm \Delta y$ in order to better understand the local and remote impacts in each of the four directions (Fig. 3-9). As in the one-dimensional 
case, we normalize the two-dimensional histograms to better understand the variation of the local response with depth (Fig. 3-10).

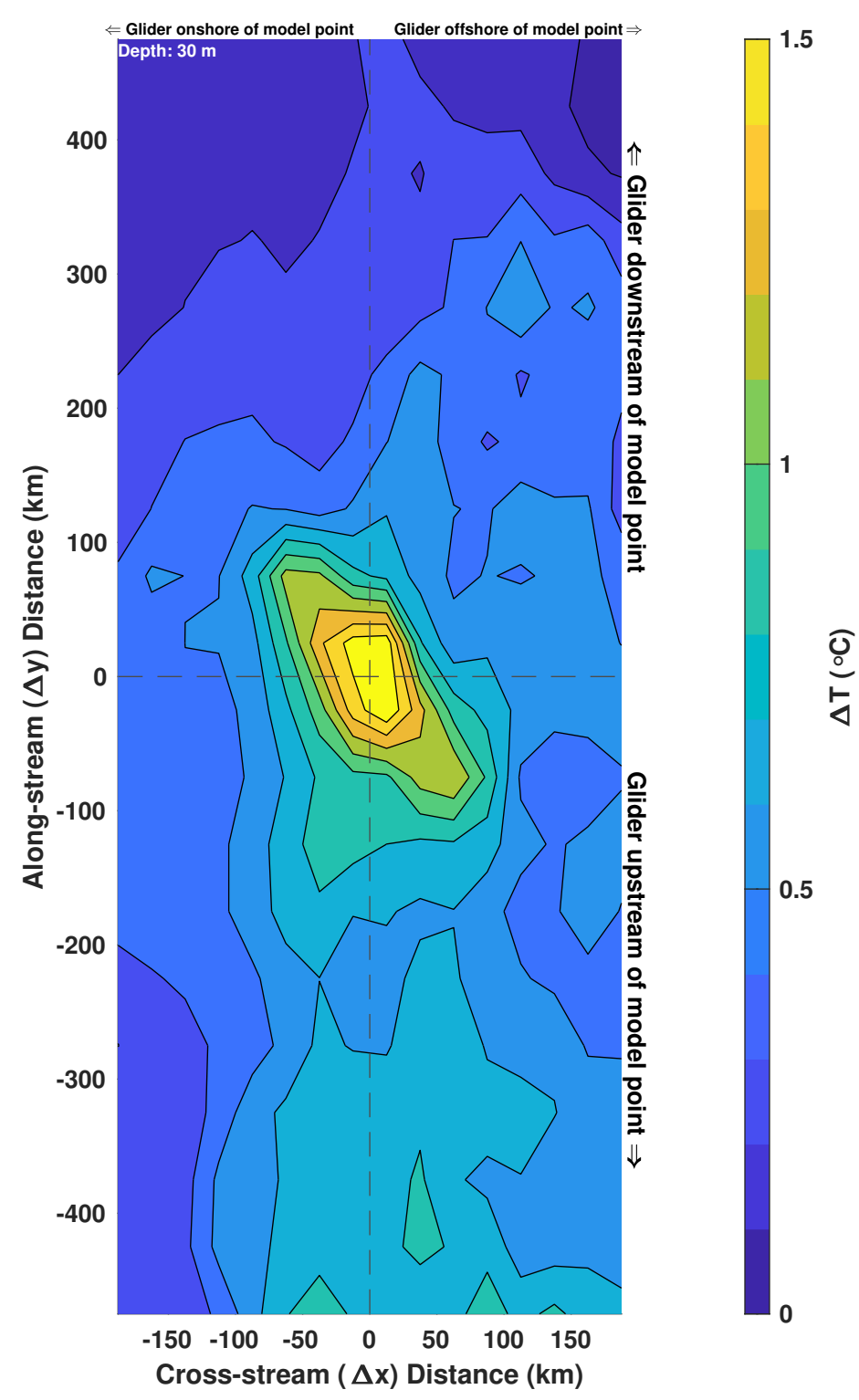

Figure 3-8: Two-dimensional contour plot of RMS temperature impact at $30 \mathrm{~m}$ depth. Black dashes at $\Delta x=0$ and $\Delta y=0$ indicate location of histograms in Figs. 3-9 and 3-10.

We focus first on the local response in the along-stream direction. There is again a clear distinction of histograms between depth ranges. The 0-200 $\mathrm{m}$ range shows a clear local maximum nearest the observations, and the decay with distance has an exponential form. In the 250-500 $\mathrm{m}$ and 600-2000 $\mathrm{m}$ depth ranges, there still appears to be some local influence, but to a lesser degree, and the decay no longer appears 
exponential. Below $2500 \mathrm{~m}$, the observational impact is small and independent of distance.

Given the shape of the normalized histograms, we can again infer that the majority of the impact from the glider observations occurs within the upper $200 \mathrm{~m}$, and thus that the exponential decay scales can be estimated in this depth range only. We then average all the histograms in the $0-200 \mathrm{~m}$ range and fit Eq. 3.1 to the $\Delta y>0$ and $\Delta y<0$ portions to determine typical length scales (Fig. 3-11). As in the onedimensional case, the resulting decay scales are $\mathcal{O}(100) \mathrm{km}$ for all three variables. The local scale of the response is generally isotropic and not strongly impacted by advection.

Unlike the local response, the remote response in the along-stream direction is asymmetric with greater model impact downstream of observations. The larger remote responses in the downstream direction of flow support the higher RMS runto-run changes in temperature, salinity, and potential density observed east of the PEACH region (Fig. 3-4). Since the fit of Eq. 3.1 only works at select depths, we use the average $\Delta_{R M S}$ for along-stream distance $\Delta y>200 \mathrm{~km}$ and $\Delta y<200 \mathrm{~km}$ to represent the remote model response at each depth. The representative values are larger for upstream observations $(\Delta y<0)$ than downstream observations $(\Delta y>0)$ (Fig. 3-9, red and black dashed lines); for example, at $30 \mathrm{~m}$, temperature, salinity, and potential density in the model change by about twice as much downstream of observations compared to upstream of observations.

In the vertical, the mean of $\Delta_{R M S}$ for $\Delta y<200 \mathrm{~km}$ is larger than for $\Delta \mathrm{y}>200 \mathrm{~km}$ throughout the upper $200 \mathrm{~m}$ (Fig. 3-12). Standard deviations of $\Delta_{R M S}$ for $\Delta y>200$ $\mathrm{km}$ and $\Delta y<200 \mathrm{~km}$ provide a measure of range dependent variability in $\Delta_{R M S}$. Differences between $\Delta_{R M S}$ averaged for upstream and downstream of observations differ by more than their respective standard errors above $200 \mathrm{~m}$. We note that in this depth range, the remote response coefficients $(B)$ from the exponential fits agree reasonably well, indicating Eq. 3.1 is a decent model of observational impact. Deeper than $200 \mathrm{~m}$, the asymmetry in along-stream impact of the glider observations becomes negligible as the overall forecast-to-nowcast change in the model becomes smaller. 
The significant asymmetry in observational impact in the along-stream direction is reflective of flow-dependence in the data assimilation process, and its tendency to elongate correlations in the along-stream direction (Cummings, 2005; Cummings and Smedstad, 2013).

In the cross-stream direction, there is no asymmetry at long range from the observations, nor do we expect there to be large remote impacts (Fig. 3-12d-f). The elevated local impact does generally extend farther offshore than inshore from a glider observation, with large $\Delta_{R M S}$ drift for $\Delta x<0$ and correspondingly longer $L$ estimates (Fig. 3-11d-f). However, the proximity of the Gulf Stream front, where large changes from $\tau_{24}$ to $\tau_{00}$ tend to occur, to the shelf means that relatively few observations are located far shoreward of these model changes, since glider observations are seaward of the $\sim 100-\mathrm{m}$ isobath. Observations farther offshore (e.g., in the Sargasso Sea) have less model impact since variability there is weaker. 

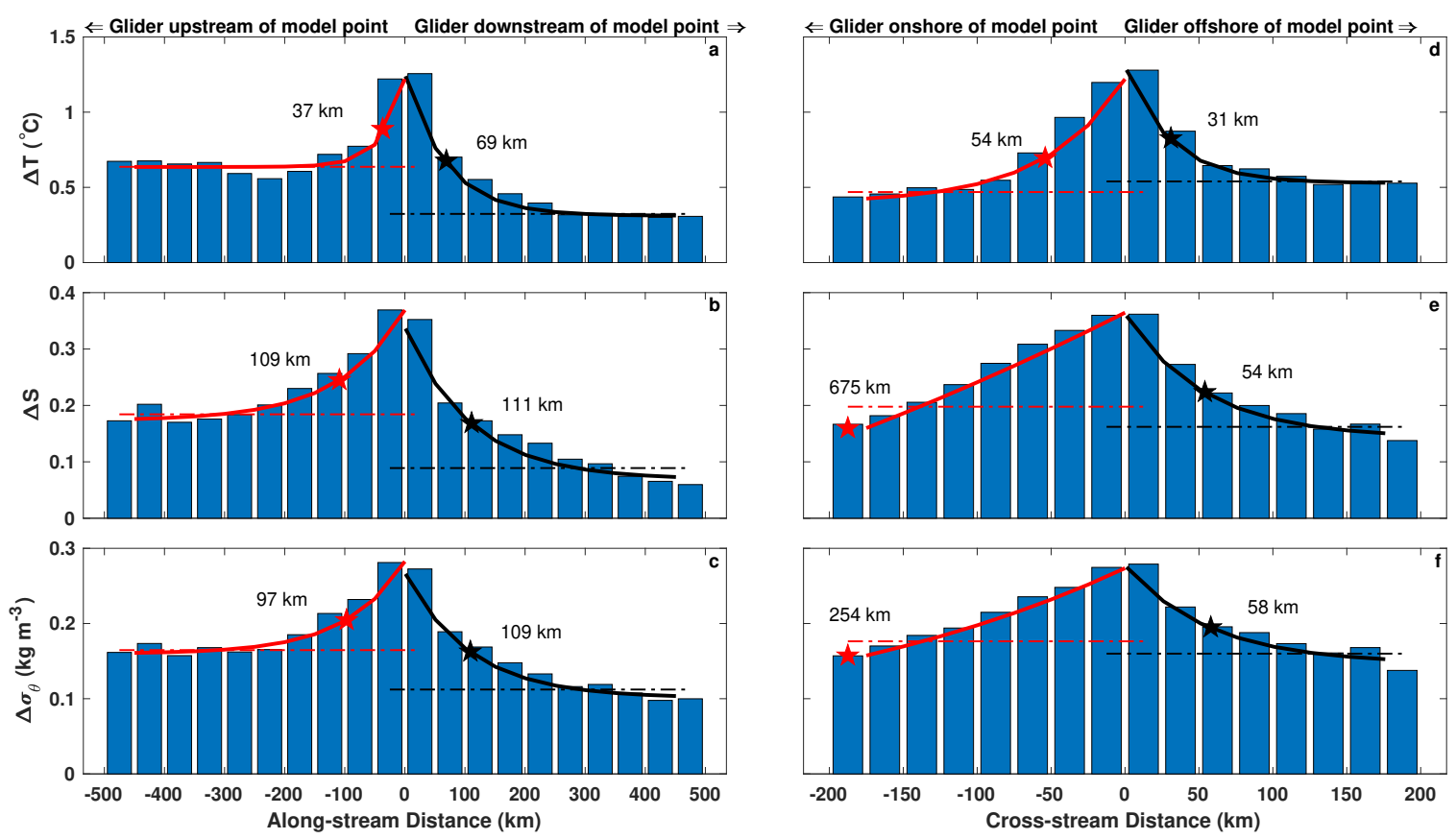

Figure 3-9: Histograms of $\Delta_{R M S}$ forecast-to-nowcast changes at $30 \mathrm{~m}$ in $(\mathrm{a}, \mathrm{d})$ temperature, $(\mathrm{b}, \mathrm{e})$ salinity, and $(\mathrm{c}, \mathrm{f})$ potential density, binned by $(\mathrm{a}-\mathrm{c})$ along-stream and (d-f) cross-stream distance from the nearest glider observation. Positive (negative) along-stream distances correspond to nearest glider observations downstream (upstream) of a model grid point. Positive (negative) cross-stream distances correspond to nearest glider observations offshore (onshore) of a model grid point. Black and red stars indicate the decay length scales for positive and negative directions. Red and black dashed lines indicate the mean outer values of the histogram for $|\Delta y|>200 \mathrm{~km}$ and $|\Delta x|>100 \mathrm{~km}$, examined further in Fig. 3-12. 

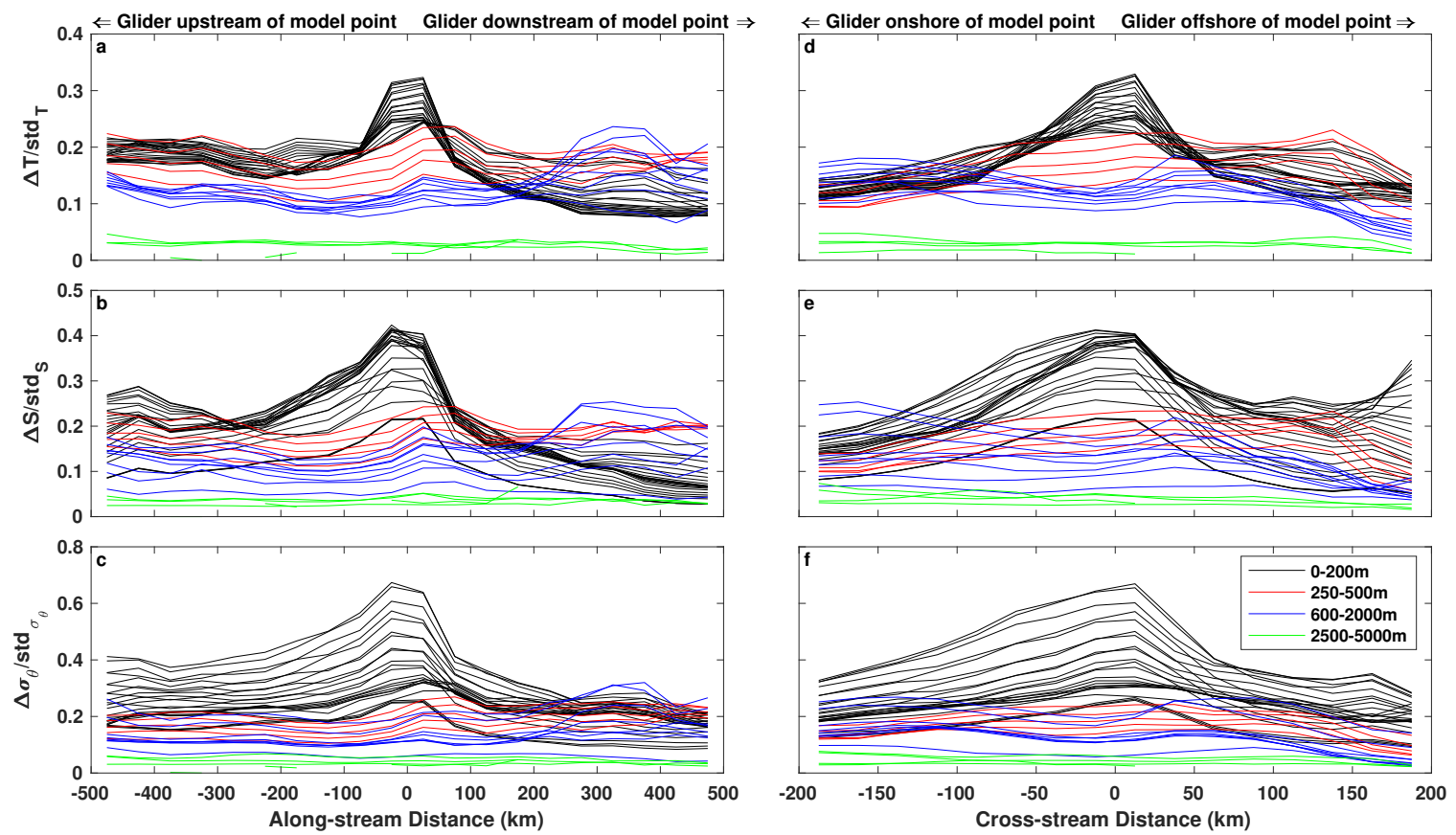

Figure 3-10: Normalized RMS-averaged forecast-to-nowcast change for each model depth level for the two-dimensional coordinate system. Temperature, salinity and potential density are displayed for all depths in the along-stream $(\mathrm{a}-\mathrm{c})$ and crossstream (d-f) directions. Color coding indicates the different depth range regimes: 0-200 m (black), 250-500 m (red), 600-2000 m (blue), 2500-5000 m (green). 

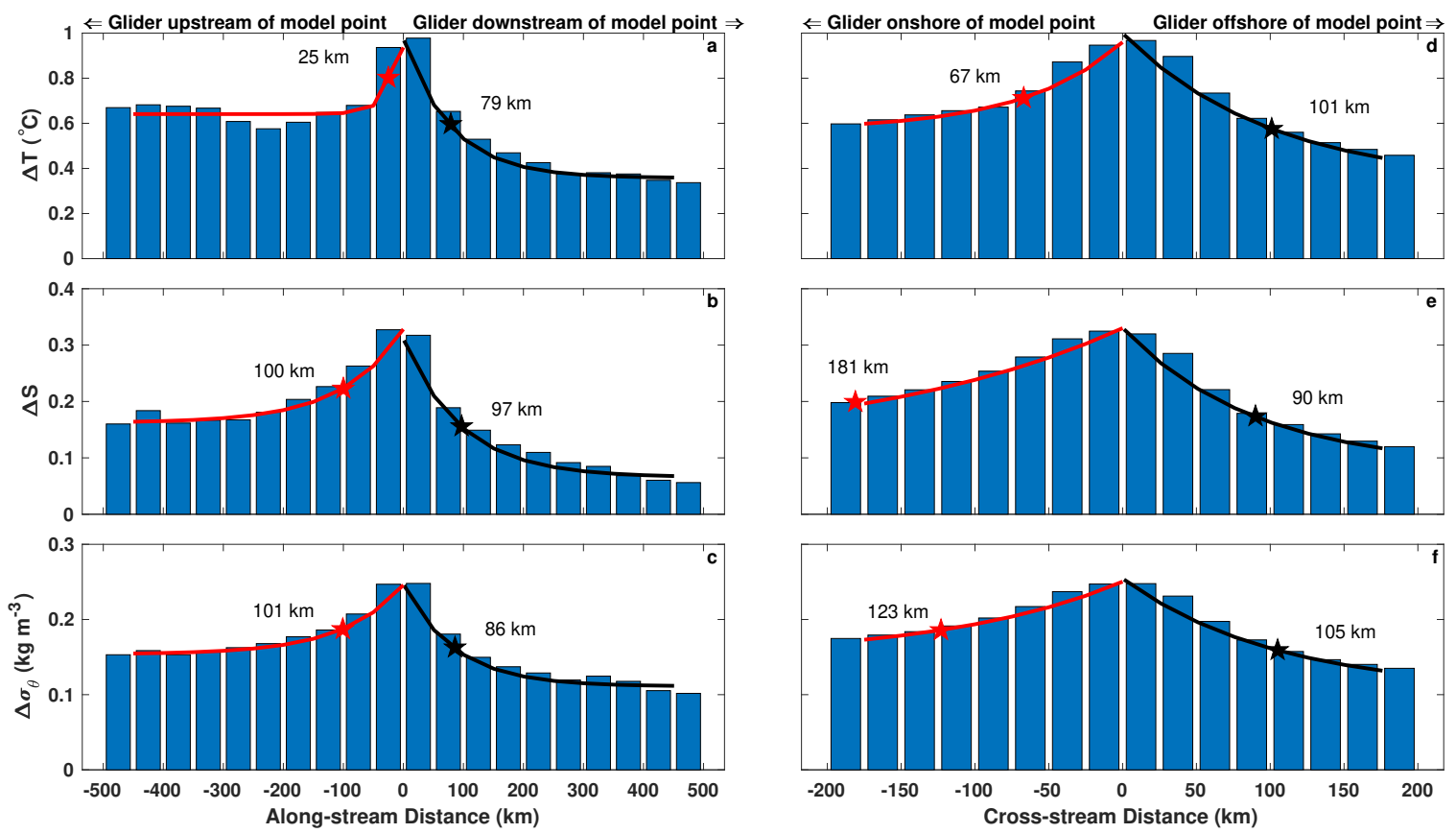

Figure 3-11: Averaged two-dimensional histograms from 0-200 $\mathrm{m}$ for temperature, salinity, and potential density in the along-stream $(\mathrm{a}-\mathrm{c})$ and cross-stream $(\mathrm{d}-\mathrm{f})$ directions. The corresponding fits and stars indicate the exponential fit and subsequent average decay length scales for the entire depth range in the positive (red) and negative (black) directions. 

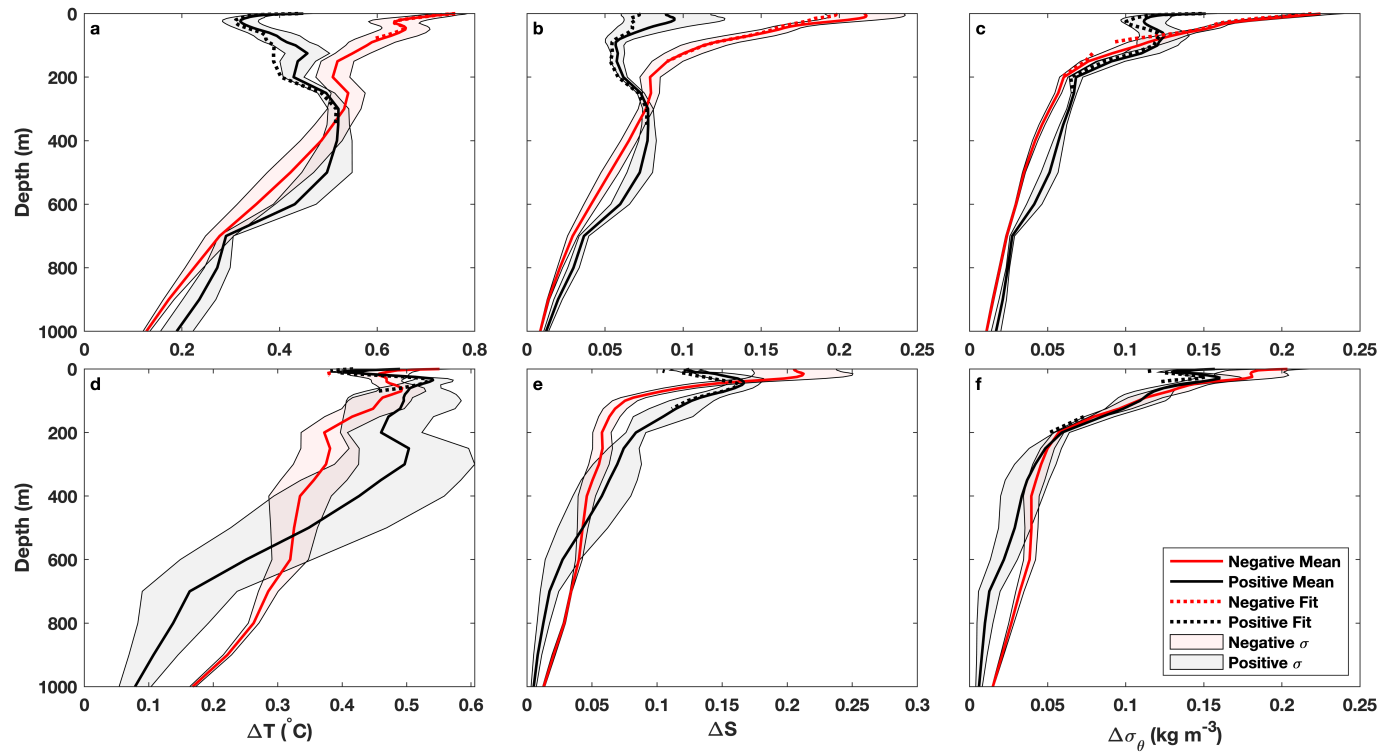

Figure 3-12: Asymptotic values as a function of depth for temperature, salinity, and potential density in the along-stream direction $(\mathrm{a}-\mathrm{c})$ and cross-stream direction $(\mathrm{d}-\mathrm{f})$. Solid black (red) lines indicate positive (negative) mean values of the histogram, and corresponding shading indicates standard deviation of the same. Dotted black (red) lines indicate those exponential asymptotic values $(B)$ for positive (negative) fits that fall within 2 standard deviations of the mean.

\subsection{NCOM Improvement from Observations}

Having established the observational impact on model forecasting capabilities over a 24-hour span, we now examine the extent to which forecast-to-nowcast changes in NCOM bring the model into better agreement with observations. We start by examining interpolated profiles for one day, drawing direct comparisons between forecast, nowcast, and the applicable observations to demonstrate the empirical improvement between model runs. For each variable, forecast and nowcast NCOM fields are interpolated to the location of each glider profile from the preceding 24 hours. Glider observations are interpolated vertically to the 40 NCOM depth levels.

For the particular example profile in Fig. 3-13, the nowcast clearly matches observed profiles of temperature, salinity, and potential density more closely than does the 24-hour-ahead forecast. Differences between the modeled and observed profiles are denoted here as $e_{i t}$ and $e_{j t}$ for forecast and nowcast errors, respectively. The 
magnitude of forecast error is larger in the upper $200 \mathrm{~m}$, where temperature and salinity differences between forecast and observations are almost twice the difference for the nowcast (Fig. 3-13d-f). Note that the density profile changes less dramatically from forecast to nowcast; this is likely due to the model's assimilation of SSH from satellite altimetry. In areas where vertical stratification is strong, the model infers the barotropic and baroclinic structures based on SSHA anomalies (Cummings, 2005; Cummings and Smedstad, 2013, 2014). It is therefore likely that NCOM greater skill in forecasting density profiles than it does the underlying temperature and salin-

ity profiles. The addition of subsurface in situ data here results in more accurate temperature and salinity profiles; this example profile was taken north of the Gulf Stream near Cape Hatteras where the presence of variable water masses like those from Mid-Atlantic Bight (MAB) resulted in the lower salinity values measured by the glider. Additionally, the nowcast captures the subsurface temperature minimum not previously seen in the 24-hour-ahead forecast.

\subsubsection{Statistical Significance of Nowcast Improvement}

While the single example above shows improvement from forecast to nowcast, we seek a more comprehensive analysis that assesses the statistical significance of forecast-tonowcast model improvements during the entire year. We test the hypothesis that the RMS difference between nowcast and observation for 2017 is smaller than the RMS difference between 24-hour-ahead forecast and observation for each variable.

Before computing RMS differences between model and observations, we remove instances in which the misfit between model and observation was more than three times the standard deviation of the misfit at a given depth. These outliers accounted for less than $2 \%$ of all available data and are predominately within $30 \mathrm{~m}$ of the surface and located at or near the 200-m isobath. This isobath corresponds to the shelf break, along which the Gulf Stream frequently flows between Florida and North Carolina. The proximity of the Gulf Stream front makes this region prone to subsurface water property variations that are difficult for the model to capture with SST and SSH data alone. One particular example of these large deviations was observed by 
PEACH gliders near Cape Hatteras, where subsurface export of MAB Cold Pool waters from the shelf resulted in uncommonly low temperature measurements (Todd, 2020), which the model likely would have been unable to forecast without sufficient in situ data. Since the observed profiles analyzed here are the unprocessed data sent to NAVOCEANO, erroneous observational measurements are also a possibility. As discussed in Section 2.2.1, we assume these were removed by NAVOCEANO in the data assimilation process, so they are also excluded from this analysis.

The close proximity of observations for a given day also provides the possibility of over-representing what the model may have deemed a 'super-observation' (Cummings, 2005). To account for this, we compute daily RMS averages of model-data differences $\left(e_{i t}\right.$ and $\left.e_{j t}\right)$ at each depth, then average over the year. The RMS averaged forecast and nowcast errors are defined here as as $g\left(e_{i t}\right)$ and $g\left(e_{j t}\right)$, respectively; they represent the 'loss functions' used in the subsequent statistical comparison. This approach reduces the number of independent realizations by an order of magnitude (now $\mathcal{O}(300)$ ).

The averaged forecast errors for temperature and salinity are generally larger than nowcast errors, especially in the upper $200 \mathrm{~m}$ (Fig. 3-14). To determine the statistical significance of this comparison, we employ the Diebold-Mariano test (Diebold and Mariano, 1995), which explicitly evaluates the accuracy of two forecasts by comparing their respective loss functions. For each NCOM depth level, we test the null hypothesis of equal forecast accuracy

$$
H_{0}: E\left[g\left(e_{i t}\right)\right]=E\left[g\left(e_{j t}\right)\right], \quad \text { or } \quad E\left[d_{t}\right]=0,
$$

where $d_{t}$ is defined as the loss differential, or the difference between both loss functions. Furthermore, as we are primarily interested in determining nowcast $\left(E\left[g\left(e_{j t}\right)\right]\right)$ improvement over the forecast $\left(E\left[g\left(e_{i t}\right)\right]\right)$, so we propose the one-sided alternative hypothesis

$$
H_{1}: E\left[g\left(e_{i t}\right)\right]>E\left[g\left(e_{j t}\right)\right]
$$

which requires a decision rule for an upper-tailed test of a $z$-statistic variant. The 
Diebold-Mariano statistic used here for large sample sizes $T$ is given by

$$
S_{1}=\frac{\bar{d}}{\sqrt{\frac{2 \pi \hat{f}_{d}(0)}{T}}}
$$

where $\bar{d}$ can be expressed as the mean loss differential and $\sqrt{\frac{2 \pi \hat{f}_{d}(0)}{T}}$ is the standard error of the loss differential. At a 95\% significance level on a standard normal distribution, the statistic must be larger than the $z_{\alpha}$ value of 1.645 . We compute the Diebold-Mariano test-statistic at each depth level and compare the results against this critical value (Fig. 3-14). The results overwhelmingly support rejecting the null hypothesis in favor of the alternative test that the forecast errors are larger than the nowcast errors at all depths except $0 \mathrm{~m}$ and $1000 \mathrm{~m}$, where observational measurements were scarce. It is thus clear that the changes to modeled fields resulting from assimilation of new observations within 24 hours of model valid time bring the operational NCOM simulations significantly closer to reality. 

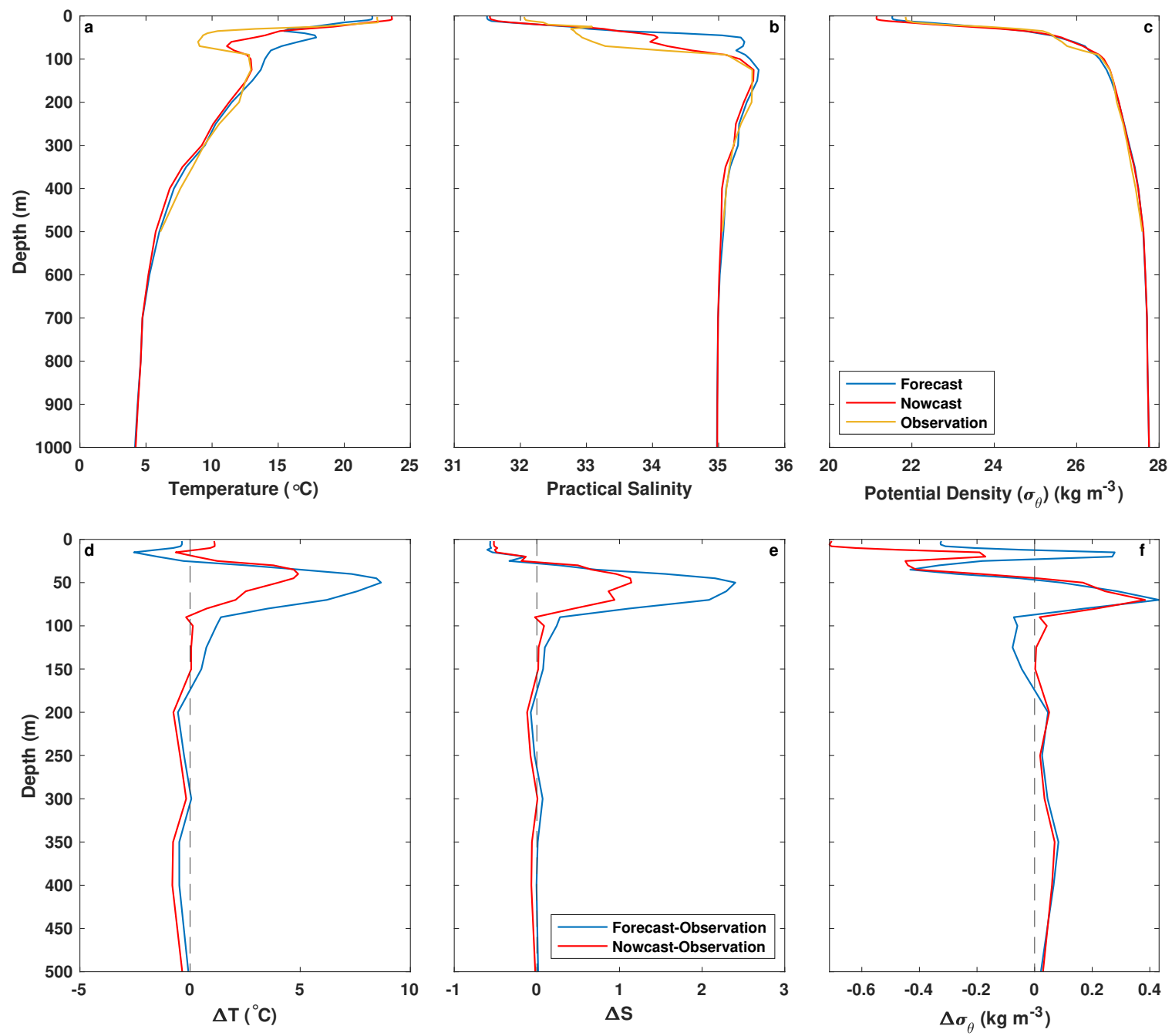

Figure 3-13: Nowcast versus forecast comparison on 09 September 2017. Interpolated forecast (blue) and nowcast (red) profiles are shown with observations from one glider profile (yellow) at $2032 \mathrm{Z}$ for (a) temperature, (b) salinity, and (c) potential density. Differences between given model run and observation are shown for $(\mathrm{d}-\mathrm{f})$ temperature, salinity, and potential density. 

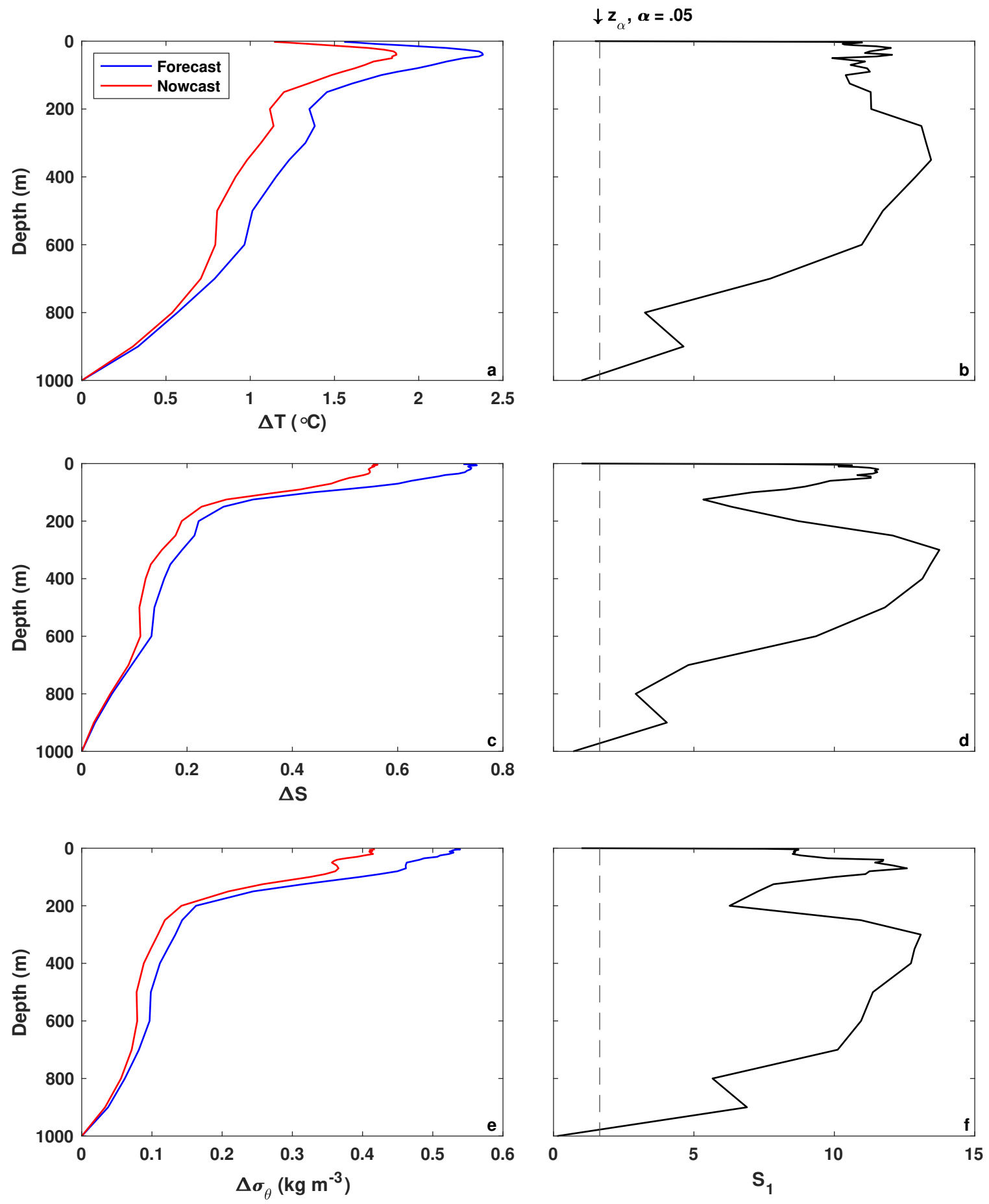

Figure 3-14: Forecast error (blue) and nowcast error (red) for (a,c,e) temperature, salinity, and potential density. Statistical significance between loss functions represented by a Diebold-Mariano test statistic value $\left(S_{1}\right.$; black) greater than the critical value at $95 \%$ significance (1.645) for (b,d,f) temperature, salinity, and potential density. 
THIS PAGE INTENTIONALLY LEFT BLANK 


\section{Chapter 4}

\section{Summary and Future Work}

This analysis characterizes the impact of underwater glider and Argo observations on NCOM numerical prediction in the Gulf Stream region. We confirm that changes in the model can be attributed to persistent glider observations, as seen with salinity measurements in the vicinity of Cape Hatteras (Fig. 3-4). The one-dimensional (Fig. 3-6) and two-dimensional (Fig. 3-10) relationships between model impact and distance from observations illustrate the large local impact of observational input within a radius of $\mathcal{O}(100) \mathrm{km}$. The local impacts of Argo observations are smaller by comparison (Fig. 3-6d-f), emphasizing the importance of glider observational focus in areas like the Gulf Stream, where large spatial gradients are difficult for the model to represent accurately. The two-dimensional analysis also shows the anisotropic features of the model (Fig. 3-8) with greater impacts downstream of glider observations as evidence of the flow-dependence within the NCOM domain (Fig. 3-12). Finally, we showed that the nowcast simulation is significantly closer to observations, presumably due to assimilation of additional observations that become available within 24 hours of the valid time (Fig. 3-14). These results highlight the importance of routine, high-resolution sampling of oceanic regions with large gradients, such as the Gulf Stream and other western boundary currents, to constrain operational ocean forecasts. Autonomous underwater gliders are particularly useful tools for such sam-

pling, particularly when piloted to repeatedly cross frontal features as is done with Spray gliders in the Gulf Stream. 
There are further applications and directions this analysis could take. As the focus here was on 2017 data only, including several years of glider data in the RMS averaging may resolve findings like the decay radius or the along- and cross-stream dependence, as noted in the two-dimensional analysis in Section 3.2.3 (Fig. 3-8). Spray gliders surveying the Gulf Stream are equipped with 1-MHz Nortek AD2CP Doppler current profilers (Todd et al., 2017), providing in situ current measurements in the Gulf Stream. While these are not reported to NAVOCEANO in real time, the processed glider velocities could be compared to the geostrophic velocity fields NCOM derives from geopotential (Cummings and Smedstad, 2013). Such comparisons could indicate the quality of the velocity predictions provided by the 3DVAR system and NCOM output. 


\section{Bibliography}

Alvarez, J. A., Strategic Implications of Continental Shelves, Naval War College Review, 22(9), 1969.

Andres, M., On the recent destabilization of the Gulf Stream path downstream of Cape Hatteras, Geophys. Res. Lett., 43(18), 9836-9842, doi:10.1002/ 2016GL069966, 2016.

Andres, M., V. Mensah, S. Jan, M.-H. Chang, Y.-J. Yang, C. Lee, B. Ma, and T. Sanford, Downstream evolution of the Kuroshio's time-varying transport and velocity structure, Journal of Geophysical Research: Oceans, 122, doi:10.1002/ 2016JC012519, 2017.

Argo, Argo float data and metadata from Global Data Assembly Centre (Argo GDAC) - Snapshot of Argo GDAC of May 2020. SEANOE., doi:https://doi.org/10.17882/ 42182\#73395, 2020.

Baringer, M. O., and J. C. Larsen, Sixteen years of Florida Current transport at 27ºN, Geophys. Res. Lett., 28(16), 3179-3182, doi:10.1029/2001GL013246, 2001.

Barron, C., A. Kara, P. Martin, R. Rhodes, and L. Smedstad, Formulation, implementation and examination of vertical coordinate choices in the Global Navy Coastal Ocean Model (NCOM), Ocean Modelling, 11, 347-375, doi:10.1016/j.ocemod.2005. 01.004, 2006.

Bloom, S., L. L. Takacs, A. Silva, and D. Ledvina, Data Assimilation Using Incremental Analysis Updates, Monthly Weather Review, 124, 1256-1271, 1996.

Burnett, W., S. Harper, R. Preller, G. Jacobs, and K. LaCroix, Overview of Operational Ocean Forecasting in the US Navy: Past, Present, and Future, Oceanography, 27, 24-31, doi:10.5670/oceanog.2014.65, 2014.

Colin, M. E. G. D., et al., Time-evolving acoustic propagation modeling in a complex ocean environment, in 2013 MTS/IEEE OCEANS - Bergen, pp. 1-9, doi:10.1109/ OCEANS-Bergen.2013.6608051, 2013.

Cummings, J. A., Operational Multivariate Ocean Data Assimilation, Quarterly Journal of The Royal Meteorological Society, 131 (613), 3583-3604, doi:10.1256/qj.05. 105, 2005. 
Cummings, J. A., and O. M. Smedstad, Variational Data Assimilation for the Global Ocean, Data Assimilation for Atmospheric, Oceanic and Hydrologic Applications, 2, 303-343, doi:10.1007/978-3-642-35088-7_13, 2013.

Cummings, J. A., and O. M. Smedstad, Ocean Data Impacts in Global HYCOM, Journal of Atmospheric and Oceanic Technology, 31(8), 1771 - 1791, doi:10.1175/ JTECH-D-14-00011.1, 2014.

Cunningham, S. A., et al., Temporal variability of the Atlantic Meridional Overturning Circulation at $26.5^{\circ} \mathrm{N}$, Science, 317, 10.1126/science.1141304, 2007.

Diebold, F. X., and R. S. Mariano, Comparing Predictive Accuracy, Journal of Business $\& 3$ Economic Statistics, 13(3), 253-63, 1995.

Douglass, E. M., and A. C. Mask, Detection of Fronts as a Metric for Numerical Model Accuracy, Journal of Atmospheric and Oceanic Technology, 36(8), 1547 1561, doi:10.1175/JTECH-D-18-0106.1, 2019.

Flagg, C. N., M. Dunn, D.-P. Wang, H. T. Rossby, and R. L. Benway, A study of the currents of the outer shelf and upper slope from a decade of shipboard ADCP observations in the Middle Atlantic Bight, J. Geophys. Res., 111, C06003, doi: 10.1029/2005JC003116, 2006.

Ford, W., J. Longard, and R. Banks, On the nature, occurence and origin of cold low salinity water along the edge of the Gulf Stream, J. Mar. Res., 11, 281-293, 1952.

Fox, D. N., W. J. Teague, C. N. Barron, M. R. Carnes, and C. M. Lee, The Modular Ocean Data Assimilation System (MODAS), Journal of Atmospheric and Oceanic Technology - J ATMOS OCEAN TECHNOL, 19, 240-252, doi: 10.1175/1520-0426(2002)019<0240:TMODAS > 2.0.CO;2, 2002.

Gawarkiewicz, G. G., R. E. Todd, W. Zhang, J. Partida, A. Gangopadhyay, M.-U.-H. Monim, P. Fratantoni, A. M. Mercer, and M. Dent, The changing nature of shelfbreak exchange revealed by the OOI Pioneer Array, Oceanography, 31(1), 60-70, doi:10.5670/oceanog.2018.110, 2018.

Goes, M., G. Goni, S. Dong, T. Boyer, and M. Baringer, The Complementary Value of XBT and Argo Observations to Monitor Ocean Boundary Currents and Meridional Heat and Volume Transports: A Case Study in the Atlantic Ocean, Journal of Atmospheric and Oceanic Technology, 37, 1-42, doi:10.1175/JTECH-D-20-0027.1, 2020.

Heiderich, J., and R. E. Todd, Along-stream evolution of Gulf Stream volume transport, J. Phys. Oceanogr., 50(8), 2251-2270, doi:10.1175/JPO-D-19-0303.1, 2020.

Hodur, R., X. Hong, J. Doyle, J. Pullen, J. Cummings, P. Martin, and M. Rennick, The Coupled Ocean/Atmosphere Mesoscale Prediction System (COAMPS), Oceanography, 15, 88-98, doi:10.5670/oceanog.2002.39, 2002. 
Imawaki, S., A. S. Bower, L. Beal, and B. Qiu, Chapter 13 - Western Boundary Currents, in Ocean Circulation and Climate, International Geophysics, vol. 103, edited by G. Siedler, S. M. Griffies, J. Gould, and J. A. Church, pp. 305-338, Academic Press, doi:10.1016/B978-0-12-391851-2.00013-1, 2013.

Jayne, S. R., D. Roemmich, N. Zilberman, S. C. Riser, K. S. Johnson, G. C. Johnson, and S. R. Piotrowicz, The Argo Program: Present and Future, Oceanography, 30(2), 18-28, 2017.

Kerry, C. G., M. Roughan, and B. S. Powell, Observation Impact in a Regional Reanalysis of the East Australian Current System, Journal of Geophysical Research: Oceans, 123, 7511-7528, doi:10.1029/2017JC013685, 2018.

Kwon, Y.-O., M. A. Alexander, N. A. Bond, C. Frankignoul, H. Nakamura, B. Qiu, and L. A. Thompson, Role of the Gulf Stream and Kuroshio-Oyashio systems in large-scale atmosphere-ocean interaction: A review, J. Climate, 23(12), 3249-3281, doi:10.1175/2010JCLI3343.1, 2010.

Lynch, J., A. Newhall, B. Sperry, G. Gawarkiewicz, A. Fredricks, P. Tyack, C. Chiu, and P. Abbot, Spatial and temporal variations in acoustic propagation characteristics at the New England shelfbreak front, IEEE Journal of Oceanic Engineering, 28(1), 129-150, doi:10.1109/JOE.2003.808833, 2003.

Metzger, E., et al., US Navy Operational Global Ocean and Arctic Ice Prediction Systems, Oceanography, 27, 32-43, doi:10.5670/oceanog.2014.66, 2014.

Miller, J. L., Fluctuations of Gulf Stream frontal position between Cape Hatteras and the Straits of Florida, Journal of Geophysical Research, 99, 5057-5064, 1994.

Olson, D., O. Brown, and S. Emmerson, Gulf Stream frontal statistics from Florida Straits to Cape Hatteras derived from satellite and historical data, Journal of Geophysical Research, 88, 4569-4578, doi:10.1029/JC088iC08p04569, 1983.

Rainville, L., C. M. Lee, D. L. Rudnick, and K.-C. Yang, Propagation of internal tides generated near Luzon Strait: Observations from autonomous gliders, J. Geophys. Res., 118, 4125-4138, doi:10.1002/jgrc.20293, 2013.

Rhodes, R. C., et al., Navy Real-time Global Modeling Systems, Oceanography, 15 (1), 29-43, 2002.

Riser, S. C., et al., Fifteen years of ocean observations with the global Argo array, Nat. Climate Change, 6, 145-153, doi:10.1038/NCLIMATE2872, 2016.

Roemmich, D., et al., On the Future of Argo: A Global, Full-Depth, MultiDisciplinary Array, Frontiers in Marine Science, 6, 2019.

Rowley, C., and A. Mask, Regional and Coastal Prediction with the Relocatable Ocean Nowcast/Forecast System, Oceanography, 27(3), 44-55, 2014. 
Rudnick, D. L., Ocean research enabled by underwater gliders, Annu. Rev. Mar. Sci., 8, 519-541, doi:10.1146/annurev-marine-122414-033913, 2016.

Rudnick, D. L., R. E. Davis, C. C. Eriksen, D. M. Fratantoni, and M. J. Perry, Underwater gliders for ocean research, Mar. Technol. Soc. J., 38, 73-84, 2004.

Schofield, O., et al., Slocum gliders: Robust and ready, Journal of Field Robotics, $24(6), 473-485,2007$.

Sherman, J., R. E. Davis, W. B. Owens, and J. Valdes, The autonomous underwater glider "Spray", IEEE J. Oceanic Eng., 26(4), 437-446, doi:10.1109/48.972076, 2001.

Shoosmith, D. R., M. O. Baringer, and W. E. Johns, A continuous record of Florida Current temperature transport at $27^{\circ} \mathrm{N}$, Geophys. Res. Lett., 32, L23,603, doi: 10.1029/2005GL024075, 2005.

Smith, S., H. Ngodock, M. Carrier, J. Shriver, P. Muscarella, and I. Souopgui, Validation and Operational Implementation of the Navy Coastal Ocean Model Four Dimensional Variational Data Assimilation System (NCOM 4DVAR) in the Okinawa Trough, pp. 405-427, Springer International Publishing, Cham, doi: 10.1007/978-3-319-43415-5_18, 2017.

Todd, R. E., High-frequency internal waves and thick bottom mixed layers observed by gliders in the Gulf Stream, Geophys. Res. Lett., 44, 6316-6325, doi:10.1002/ 2017GL072580, 2017.

Todd, R. E., Export of Middle Atlantic Bight shelf waters near Cape Hatteras from two years of underwater glider observations, J. Geophys. Res., 125, e2019JC016,006, doi:10.1029/2019JC016006, 2020.

Todd, R. E., Gulf Stream mean and eddy kinetic energy from Spray underwater glider measurements [Data set], doi:10.21238/S8SPRAY2675A, 2021.

Todd, R. E., and L. Locke-Wynne, Underwater glider observations and the representation of western boundary currents in numerical models, Oceanography, $30(2)$, 88-89, doi:10.5670/oceanog.2017.225, 2017.

Todd, R. E., D. L. Rudnick, J. T. Sherman, W. B. Owens, and L. George, Absolute velocity estimates from autonomous underwater gliders equipped with Doppler current profilers, J. Atmos. Oceanic Technol., 34(2), 309-333, doi: 10.1175/JTECH-D-16-0156.1, 2017.

Todd, R. E., et al., Global perspectives on observing ocean boundary current systems, Front. Mar. Sci., 6(423), doi:10.3389/fmars.2019.00423, 2019.

Webb, D. C., P. J. Simonetti, and C. P. Jones, SLOCUM: an underwater glider propelled by environmental energy, IEEE Journal of Oceanic Engineering, 26 (4), 447-452, doi:10.1109/48.972077, 2001. 